\title{
MOOC design \\ - Dissemination to the masses or facilitation of social learning and a deep approach to learning?
}

\section{Inger-Marie F. Christensen}

Senior e-learning advisor

Centre for Teaching and Learning, University of Southern Denmark. Project manager and consultant on the Hans Christian Andersen MOOC project.

\section{Mette Dam Laursen}

MA in comparative literature and course host Centre for Teaching and Learning, University of Southern Denmark. Produces materials for and acts as course host on the Hans Christian Andersen's Fairy Tales MOOC.

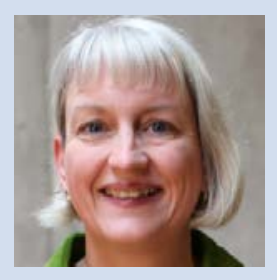

\section{Jacob Bøggild}

\section{Professor}

The Hans Christian Andersen Centre, Department for the Study of Culture, University of Southern Denmark. Doing research in the modern aspects of the writings of Hans Christian Andersen.

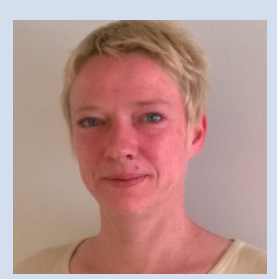

\section{Torsten Bøgh Thomsen}

\section{PhD student}

The Hans Christian Andersen Centre, Department for the Study of Culture, University of Southern Denmark. Currently studying ecocriticism, posthumanism and new materialism in a historical perspective with particular focus on the work of Hans Christian Andersen and the

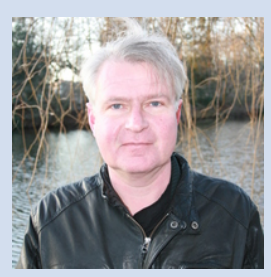
deliberations on nature and materiality that it offers.

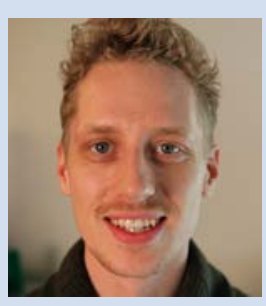




\section{Abstract}

This article accounts for the design of the massive open online course (MOOC) Hans Christian Andersen's Fairy tales on FutureLearn and reports on the effectiveness of this design in terms of engaging learners in social learning and encouraging a deep approach to learning. A learning pathway was designed that provided learners with relevant knowledge, allowed them to practice their analysis skills and provided model responses. In the first run of the MOOC, a light facilitation approach was used to motivate and engage learners. In the second run, this was supplemented with live $\mathrm{Q} \& \mathrm{~A}$ sessions and increased educator feedback. Course data show that that some learners use the space provided for social interaction and mutual support. A learning pathway that engages learners in discussion and progression from week to week facilitates a deep approach to learning. However, this requires more support from the educators and the course host.

\section{Introduction}

In autumn 2015, the Hans Christian Andersen Centre at the University of Southern Denmark in collaboration with the Centre for Teaching and Learning carried out its first MOOC titled Hans Christian Andersen's Fairy Tales (HCA MOOC) on the FutureLearn platform. This article will account for the learning design of the HCA MOOC and the underlying pedagogical considerations and intentions with regard to learning outcomes and the production and selection of course materials and activities. The idea was not to deliver content only, but to engage learners in conversations on the author and his works in an attempt to mirror classroom conversations facilitating social learning and a deep approach to learning. The question then was how to create a learning design that would enable this.

Datasets on learner engagement from the FutureLearn platform together with learners' evaluation will be presented, discussed and compared to the intentions of the learning design with the aim of assessing the effectiveness. Against this background, the article aims to present conclusions to these key issues:

- How do you design for social learning and encourage a deep approach to learning?

- How do you support learning and learner interaction when a MOOC is live?

As such, this article is a response to the call for case studies on how to design M00Cs that engage and support learners (Yosef et al., 2014; Raposo-Rivas et al., 2015; Christensen, 2016 and Ferguson et al., 2015) and it builds on the research that has been undertaken to identify and understand learner engagement patterns in MOOCs (Ferguson \& Clow, 2015 and Ferguson et al., 2015). However, individual course design 
components are in focus in an attempt to identify the components that show the greatest potential with regard to engaging learners.

\section{Why design and deliver a MOOC?}

The HCA MOOC was designed as a research showcase in Czerniewicz et al.'s terminology. This category of MOOCs is "[e]xemplified by specialised indepth courses in which an institution's research is showcased, raising the appeal of the institution as a centre of excellence" (Czerniewicz et al., 2014:130). Research showcase MOOCs attract people with university degrees and/or with a special interest in the topic who would like to gain in-depth information, experience the context and discover how research is conducted.

The intention was to reach out to a global audience to disseminate and discuss knowledge and views on Hans Christian Andersen and his works. As such the MOOC was part of the non-formal learning landscape and an "out-ward focused course where participants have little or no connection to the institution" (Czerniewicz et al., 2014:126). The purpose was, furthermore, to gain knowledge and experiences with regard to designing and delivering online learning to inform teaching and learning at the university.

\section{Challenges involved in designing a MOOC}

MOOCs have existed since 2008 (McAuley et al., 2010 and Yousef et al., 2014) and the hype around the online phenomenon peaked in 2012 which has been called "The Year of the MOOC" (Pappano, 2012). MOOCs were first acclaimed as pedagogic innovation and a threat to formal education. From the point of view of the learning sciences, however, many M00Cs cannot be described as new pedagogy (Eisenberg \& Fischer, 2014; Daniel, 2012; Rai \& Chunrao, 2016; Haggard, 2016; Ferguson \& Sharples, 2014; Yousef et al., 2014 and Christensen, 2016). Instead they keep the traditional lecture format alive; now in an electronic version and via MOOC platforms that secure delivery to tens of thousands of students world-wide.

In the early days of the MOOCs, two distinct pedagogical directions formed;

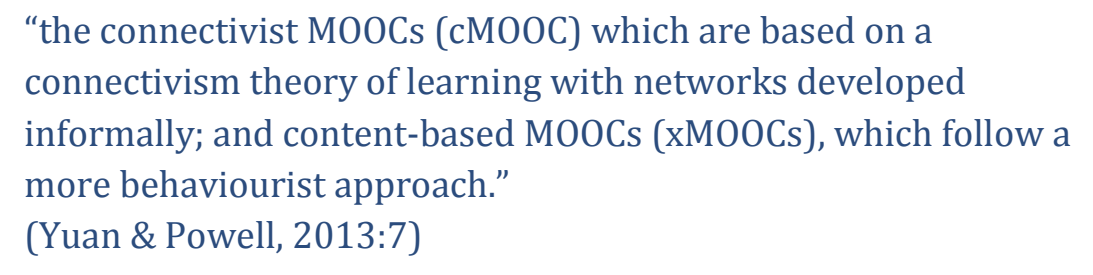

The cM00Cs explored and challenged traditional teaching by applying new pedagogies and can thus be said to be more innovative than the xMOOCs that are "essentially an extension of the pedagogical models practised within the institutions themselves" (Yuan \& Powell, 2013:7). 
The cMOOC versus XMOOC debate reflects the debate between researchers and educators regarding whether to focus on the learning process or the learning content in course design (Yuan \& Powell, 2013) and regarding how to view learning, applying the participation or the acquisition metaphor (Kop, 2011). These two metaphors also mirror the two major traditions in e-learning; "the first one has communication and interaction between people at the heart of learning, and the second focuses on engagement with resources" (Kop, 2011:19).

Today, a wide variety of MOOC types exist (Heilesen, 2014 and Czerniewicz et al., 2014), and this variety is supported by the establishment of MOOC platforms in Europe, such as the FutureLearn platform.

When it comes to designing and delivering MOOCs, a major challenge is how to design for "massive"; how do you create a sense of community with a large cohort? Pedagogy, supporting learners and facilitating quality learning are emphasised as some of the challenges of the MOOC format (Haggard, 2016; Raposo-Rivas, 2015 and Ferguson \& Sharples, 2014).

In the light of this, it is important to set new agendas for MOOC design and to experiment with new pedagogies that focus on learners and the quality of learning (Eisenberg \& Fischer, 2014 and Rai \& Chunrao, 2016). This is increasingly recognised by educators and universities who view MOOCs as arenas not only for showcasing and brand-building (Czerniewicz et al., 2014) but also for experiments to investigate how to enhance students' learning outcomes and develop new formats for online learning (Czerniewicz et al., 2014; University of Edinburgh, 2013; Daniel, 2012; Yousef et al., 2014 and Christensen, 2016). These experiments should build on learning in a digital age (Christensen, 2016) and "conceptualize learning as an inclusive, social, informal, participatory, and creative lifelong activity" (Fischer, 2015:4).

\section{The FutureLearn platform and social learning}

When a platform was selected for the HCA MOOC, FutureLearn was seen as the best match because the Hans Christian Andersen Centre wished to engage a global audience in discussions on the author and his works. The intention was not simply to disseminate knowledge but to support social learning and encourage a deep approach to learning.

FutureLearn launched its first course in 2013 and is wholly owned by the Open University, UK (FutureLearn, undated). More than 5 million people have created accounts on FutureLearn which has 94 partners and claims to be a platform based on social-constructivist pedagogy which sets it apart from the major US platforms with their "lecture-based approach" (Walton, 2014; Ferguson \& Sharples, 2014; Ferguson et al., 2015 and Ferguson \& Clow, 2015). 
The FutureLearn platform supports

"a social-constructivist pedagogy, based on the Conversational
Framework [...] In brief, this is a general theory of effective
learning through conversations, with oneself and others, about
the immediate world and about abstract concepts. To engage in
successful conversations, all parties need access to a shared
representation of the subject matter as well as tools for
commenting, responding and reflecting."
(Ferguson \& Sharples, 2014:101)

The FutureLearn pedagogy is a response to the question "Which successful pedagogies can improve with scale?" (Sharples et al., 2014). The personal tutoring pedagogy of the Open University is an effective method but very costly when scaled. Direct instruction as delivered by many MOOCs on the Coursera platform e.g. (Yousef et al., 2014 and Paposo-Rivas, 2015) is very scalable "but they are not very effective in engaging people in active and reflective learning" (Sharples et al., 2014:9). A social-constructivist pedagogy based on the Conversational Framework, as described above, is believed to be a possible solution. The approach is also labelled networked or social learning and the idea is that learners on MOOCs support each other and benefit from a social learning effect made possible by the massive number of learners:

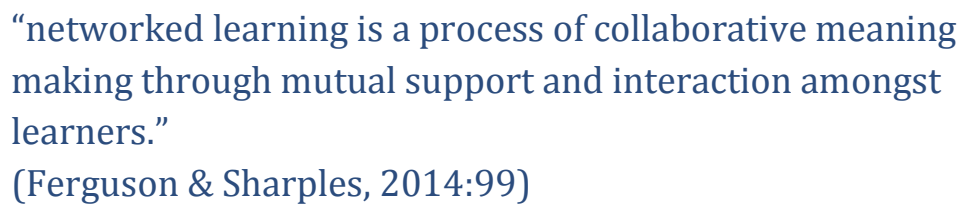

When designing courses on the FutureLearn platform, partners can choose between a range of tools and functionalities that all support the pedagogic aims of FutureLearn which are listed below:

The pedagogic aims of FutureLearn

- Direct learning, one learner answers another's questions

- Knowledge sharing, a learner shares information or skills with others

- Conversational learning, where learners explore ideas through a sustained dialogue

- Vicarious learning, learning by observing the activity of others

- Implicit learning, learning things through the act of collaborating on a shared representation

- ZDP (Zone of Proximal Development) where you learn from someone with more knowledge or experience

(Walton, 2014:1)

Figure 1. The pedagogic aims of FutureLearn. 
Course design on the FutureLearn platform and the actual design of the HCA MOOC are described in detail below.

\section{Learner engagement in MOOCs}

Understanding learner engagement in MOOCs is important and should inform course design. However, experiences from traditional campus based classes cannot be transferred to MOOCs. Different types of learners will enrol in MOOCs for different purposes and consequently display different behaviours (Anderson et al., 2014).

Especially the concept of completion is complex when it comes to MOOCs. It is often stated that MOOC completion rates are as low as 5 to $10 \%$ (Rai \& Chunrao, 2016). However, this does not make much sense in a free, online, course with open access and with the course staying open after the formal end date (Anderson et al., 2014 and Heilesen, 2014). Fischer recommends ignoring completion rates, i.e. the percentage of enrolled learners who finish. Instead he suggests looking at the actual number of people who finish the course. He states that usually this figure is higher than the total number of students taught by the educator in conventional courses in his/her lifetime (Fischer, 2015). Ferguson \& Clow compare enrolment in a MOOC "to bookmarking a web site or placing an item temporarily in an online shopping basket" (2015:52). Enrolment signals interest but not necessarily a wish to start, let alone complete a course. Instead the number of people who actually starts a course, should be taken as a point of departure with respects to completion rates. So what are the success criteria? McAuley et al. suggest letting learners themselves define these:

"The MOOC is open and invitational. No one who wishes to
participate is excluded; people negotiate the extent and nature of
their participation according to their individual needs and
wishes, regardless of whether those needs are defined, for
example, by personal interest or workplace requirements."
(McAuley et al., 2010:5)

This is supported by Walton, who recommends enabling participation at multiple levels. He states that many learners do not wish to engage socially but "should benefit by vicariously learning from seeing others ask questions, share knowledge and discuss ideas" (Walton, 2014:2).

In the HCA MOOC, the main goal was to engage learners in social learning and encourage a deep approach to learning with regard to the author and his works. Therefore, the overall success criterion was to motivate learners to, first and foremost, engage in online conversations by posting and replying to comments, but also to submit the peer reviewed assignment that marked the end of the course. Learners who displayed this type of behaviour are labelled social learners below. 


\section{FutureLearn course designs}

FutureLearn creates a space for the course on the platform, and partners then populate the course with activities and materials. A course on the FutureLearn platform is divided into activities. Each activity contains a series of steps. A step can be a short article, a video, a quiz, a discussion, further resources etc. The learner can mark a step completed and/or move on to the next step. The intention is that the learner moves through the steps in a linear fashion. However, the learner can decide him/herself how much time to spend on a step or whether to skip it all together. Learners can participate in the course free of charge. A learner has earned and can buy a statement of participation from FutureLearn when he/she has completed $50 \%$ of the steps.

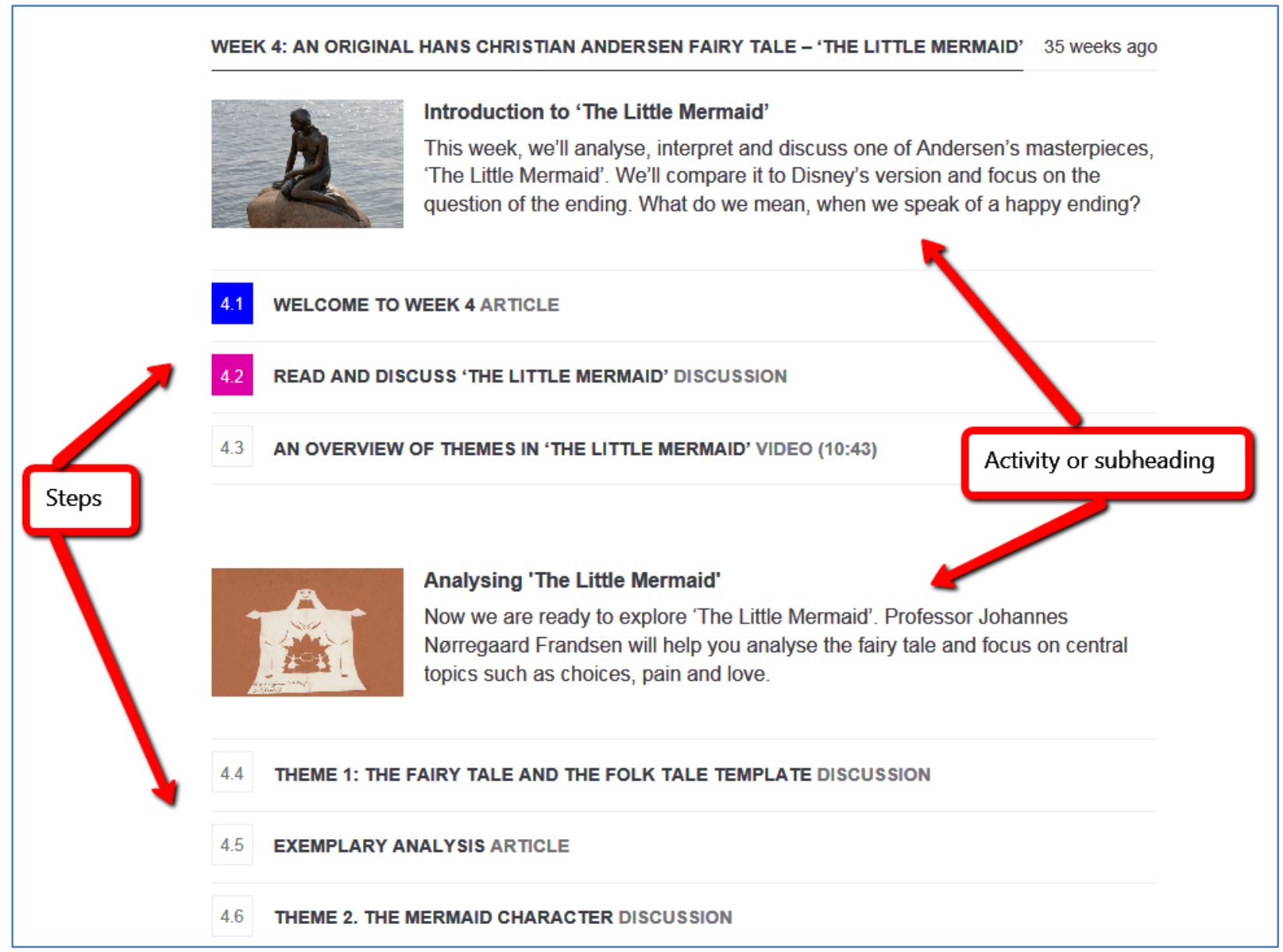

Figure 2. Activities and steps on the FutureLearn platform

For each step in the course, a comment section is available, giving learners the possibility to comment directly on an article, discussion or video. This approach is labelled "inline conversation" or "free-flowing discussion" and distinguishes the FutureLearn platform from most US MOOC platforms where discussions are allocated to separate forums (Walton, 2014; Ferguson \& Sharples, 2014 and Ferguson et al., 2015). 
Inline conversation contextualises participants' learning and facilitates knowledge sharing together with conversational and implicit learning cf. figure 1 above. In the HCA MOOC conversational learning can happen when learners post their own fairy tale analysis and give feedback on the analyses of other learners. In some cases, learners will collaborate to develop a shared understanding of how to interpret a fairy tale and this will be a case of implicit learning. The creation of a rich and dynamic virtual learning environment is supported, and participant interaction as well at the learning outcome of the individual learner is enhanced, since content, activities and learner reflections are linked together (Walton, 2014; Ferguson \& Sharples, 2014 and Ferguson et al., 2015). The act of verbalising thoughts and ideas enables social constructivist learning in that language is needed to express "complex propositions and relationships between concepts that are not practicable in other forms of communication" (Laurillard, 2012:50).

Inline conversation also provides feedback to educators concerning learners' understanding, struggles and progress, and educators can respond to the discussion to support learners (Walton, 2014 and Ferguson \& Sharples, 2014).

An activity feed in the course helps learners discover interesting content and makes visible any questions asked by learners. The activity feed shows recent comments and thus focuses learners' attention on what is happening right now. This should lead to questions being answered more quickly and support direct learning, cf. figure 1 above, and the creation of a learning community (Walton, 2014 and Ferguson \& Sharples, 2014).

Learners also have the possibility to follow other learners and educators. The latter makes the educators less distant and the former helps build "lightweight connections" that can grow into networks of learners that mutually support each other. Learners can see the activity of those they follow, which filters interaction and reduces information overload (Walton, 2014 and Ferguson \& Sharples, 2014). 


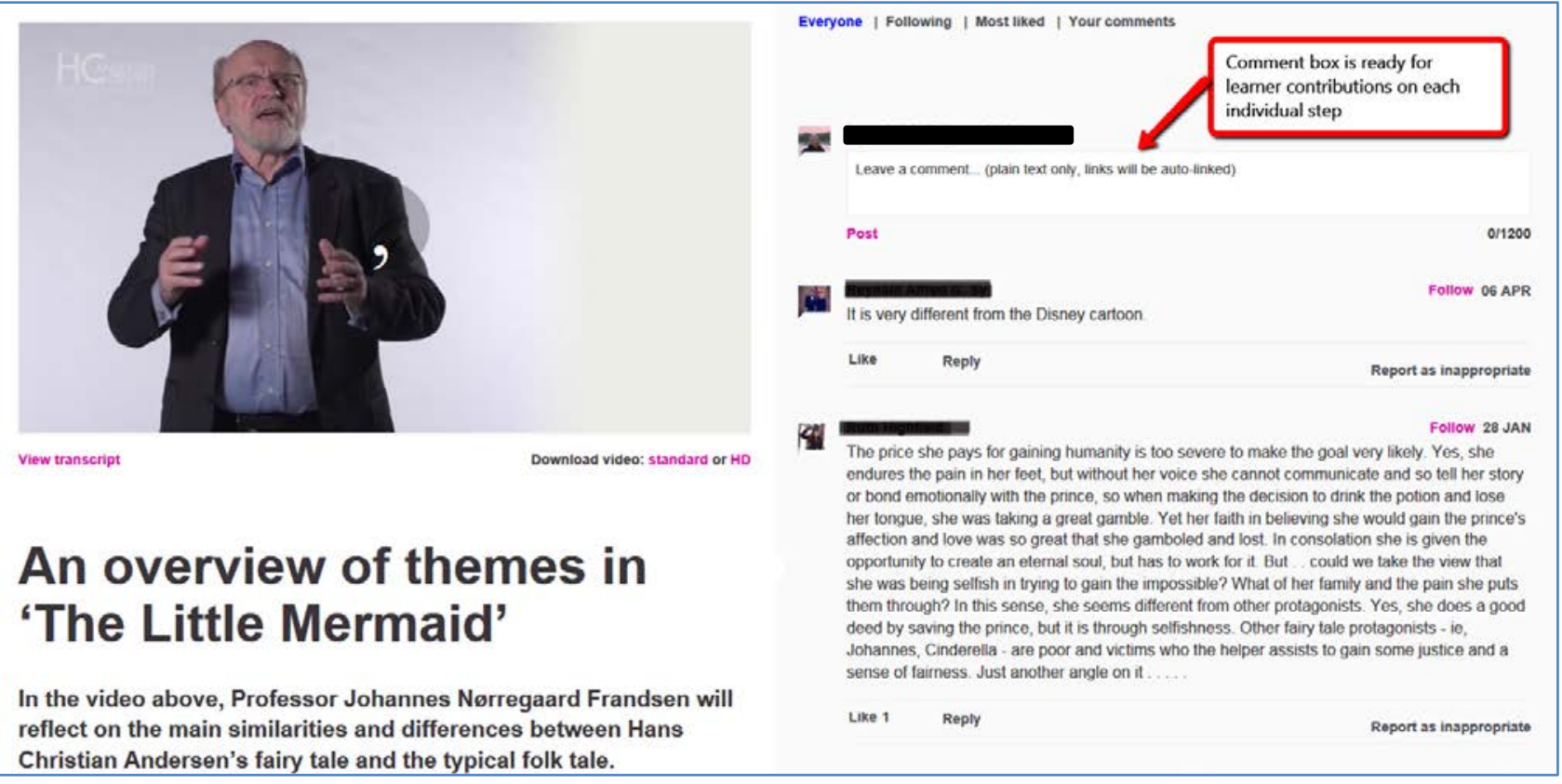

Figure 3. Inline conversation on FutureLearn.

\section{First run - the HCA MOOC learning design}

The main objective of the course was to convey the facts that Andersen is an author who wrote as much for adults as for children, who addressed key issues of his time in a modern fashion and whose works are richer and more complex than one would gather from the 10 to 15 tales his worldwide fame rests upon. Furthermore, the educators wanted to discuss the degree of contemporary relevance and the degree of universality of Andersen with a global audience of the present day.

The tales selected for the course comprised well known and less familiar ones. It was believed that the well-known ones would motivate people to enrol for the course. The less familiar ones would help highlight the richness and complexity of Andersen's works. Moreover, it was decided that some of the tales should reflect Andersen's background in a Christian culture and his preoccupation with religious themes which were pertinent to his age. This would be an ideal basis for the discussion on the degree of modern-day relevance and universality of Andersen.

These considerations led to the selection of "The Tinder-Box", "The Traveling Companion", "The Little Mermaid", "The Story of a Mother", "The Snow Queen" and "The Red Shoes". Furthermore, two folk tales that had inspired the author were included which would allow for a vital comparison with Andersen's mode of playing on and manipulating the basic elements and structures of the folk tale.

The following learning goals were formulated for the HCA MOOC: 


\section{By taking this course, you will:}

- Gain knowledge on the life and works of the writer Hans Christian Andersen.

- Gain knowledge on the fairy tale genre.

- Be able to discuss, analyse and interpret fairy tales using relevant models.

- Gain insight into the themes embedded in Hans Christian Andersen's fairy tales.

- Be able to reflect on and discuss Hans Christian Andersen's topicality and cross-cultural relevance.

Figure 4. Learning goals of the HCA MOOC.

One major reason why the richness and complexity of Andersen's stories have not been recognized internationally is the lack of quality of the translations. Most translators have seen their target audience as children and have ironed out anomalies and softened the violent and sexual motifs in the stories. This has resulted in sanitised and imprecise versions; therefore new English translations more loyal to the Danish originals were included in the course.

\section{Providing participants with analysis tools}

As mentioned, Andersen plays on and manipulates the basic elements and structures of the folk tale. These constitute a prism through which Andersen could reflect on problems and issues pertaining to his age which he would otherwise not have been able to address. The modernity of Andersen is very much rooted in this aspect of his writing. Therefore, it was decided to incorporate a theoretical foundation for the course. This consisted of the actantial model as developed by Greimas (Hébert, 2006) and the so-called "home-away-home-structure". The actantial model is a further development of Propp's work (Propp, 1928) and is presently used in the analysis of popular genres of fiction. The home-away-home-structure is basic to many narratives, but has its source of origin in folk tales. These two simple models provided participants with very accessible and easily comprehensible analysis tools which would enable them to analyse Andersen's modus operandi in a fairly advanced way.

\section{Designing a learning pathway for social learning and a deep approach to learning}

The educational psychologists Marton \& Säljö (1976) have introduced the idea that when university students undertake an academic task they can adopt either a learning approach focused on understanding (the deep approach) or a learning approach focused on reproducing (the surface approach). The deep approach to learning is typified by an intention to understand and seek meaning, leading students to attempt to relate 
concepts to their existing understanding and to each other, to distinguish between new ideas and existing knowledge, and to critically evaluate and determine key themes and concepts. The surface approach to learning is typified by an intention to complete the task and memorise information, making no distinction between new ideas and existing knowledge and to treat the task as externally imposed.

The HCA MOOC was designed to support a deep approach to learning even though it reached out to a global and massive audience. The objective was to study Hans Christian Andersen's fairy tales in the context of meaning making. In order to invite the participants to engage with this objective, a learning pathway was designed that would allow participants to build knowledge progressively (Jih, 1996).

The HCA MOOC was designed as a 6-week course with the following topics:

\section{Overview of the HCA MOOC}

\section{Week 1: Introduction}

Week 2: Hans Christian Andersen's fairy tales and the folk tale inspiration

Week 3: Hans Christian Andersen's experimental rewritings of folk tales Week 4: An original Hans Christian Andersen fairy tale - 'The Little Mermaid'

Week 5: Hans Christian Andersen's new fairy tales

Week 6: Hans Christian Andersen's recycling of the folk tale with 'The Red Shoes', peer reviewed essay and further studies

Figure 5. The HCA MOOC.

Participants are provided with background information on Andersen and his contemporary society in week 1 . In week 2 participants learn about the analysis models that they are to use when analysing and discussing the fairy tales included in the MOOC and they are guided through their first analysis. From week 2 participants are to undertake their own analyses and discuss possible interpretations of the fairy tales. The learning pathway that was designed to facilitate this process is illustrated below: 


\section{The learning pathway of the HCA MOOC}

1. Introduction to the fairy tale to be read - article step.

2. Participants are asked to read and discuss their first impressions of the fairy tale - discussion step.

3. Video introduction highlighting the themes embedded in the fairy tale and including passages from the fairy tale read aloud

4. Participants analyse theme 1 guided by specific questions posed by the educator. Participants post their contributions and can read and comment on the contributions of other learners discussion step.

5. Participants are presented with the educator's sample analysis article step.

Items 4 and 5 are repeated for each theme.

Figure 6. The learning pathway of the HCA MOOC.

Each week includes one or more quizzes to give participants the opportunity to self-assess their understanding. The quizzes do not count toward an overall score. Week 6 of the course contains a summary of the course and a peer-reviewed essay assignment on the topicality and universality of Andersen. Like the quizzes, this assignment does not count toward an overall score.

Course design overview The first course run consisted of 102 steps. See step distribution on type in the figure below. 


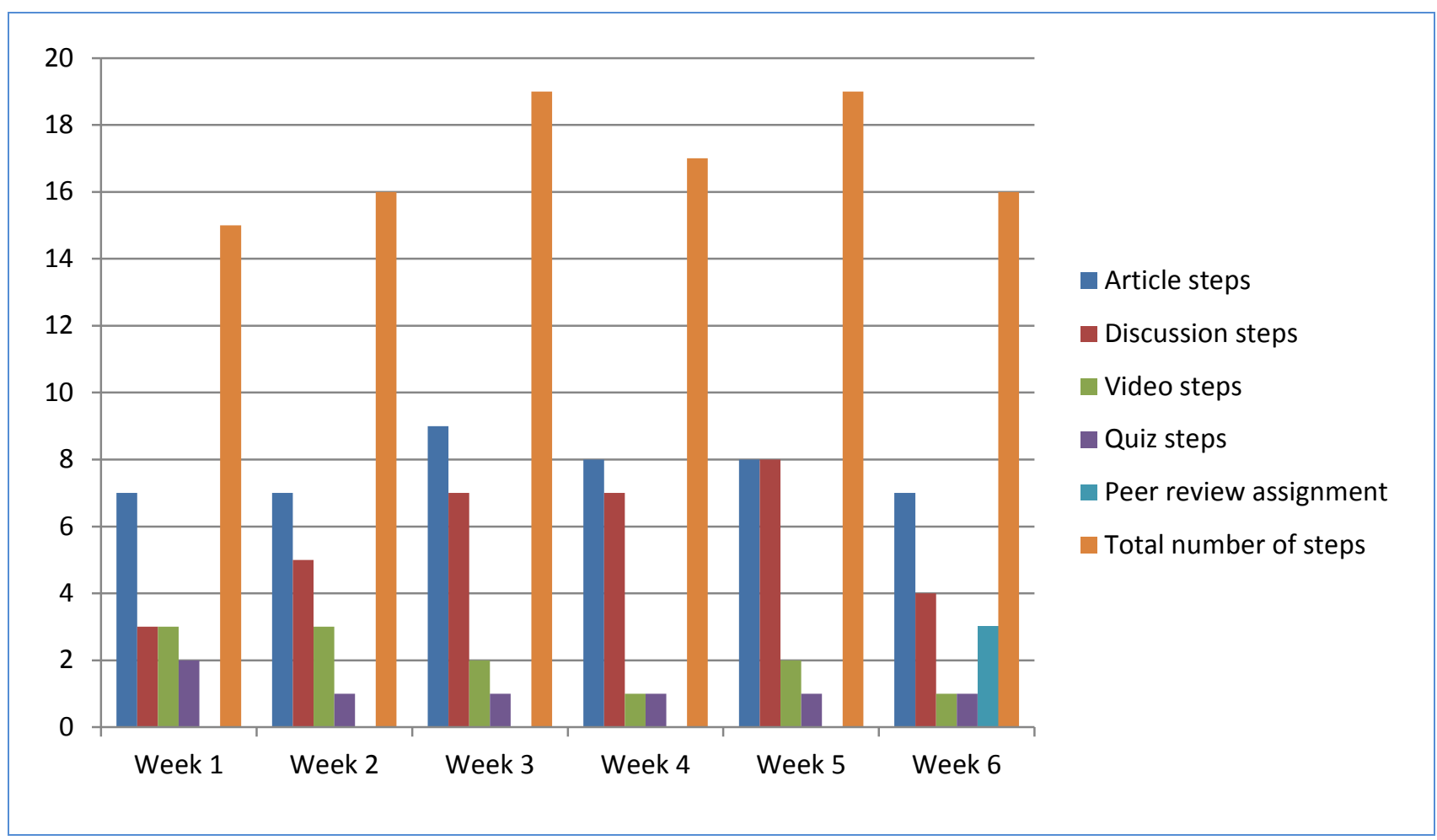

Figure 7. Number of steps per week distributed on step type and week totals.

\section{Involving participants from the beginning}

It is a FutureLearn principle to invite participants to contribute early on in the course to engage and motivate to active participation. This was attempted by adding the following step to week 1 : 


\title{
Your turn to introduce yourself
}

\author{
Let's start by sharing the stories of when and how we were first \\ introduced to Hans Christian Andersen and his fairy tales. \\ Below you can read about professor Jacob Bøggild's first encounter \\ with Hans Christian Andersen and we would love to hear when and how \\ you were first introduced to the author yourself.
}

"My first serious encounter with the fairy tales and stories of Hans Christian Andersen was probably quite unusual. They were not a part of my childhood. Nobody read them aloud to me. My father preferred to read Kipling and Jules Verne to me. I guess they interested him more (no, I do not guess, they most certainly did...). So I only started to read Andersen as a student of literature. And I was not captured by the stories themselves, really. I was captured by the way they are told! My first favourites were "The Shadow", "The Little Mermaid" and "Auntie Toothache". They are still my favourites along with "The Snow Queen", "The story of a Mother" and some of the tales where things are the protagonists."

Share the story of your first encounter with Hans Christian Andersen with us and with other learners by posting a comment in the discussion section at the bottom of this page. If you read a comment from someone else that you find really useful or interesting, click the Like button!

Figure 8. Step 1.4 Your turn to introduce yourself.

For each fairy tale in the course was also added an introductory read and discuss step to encourage participants to share their immediate thoughts on the fairy tale and their experience reading it. In many cases, article and video steps contain questions for reflection to encourage learners to consider certain aspects of the resources provided in the step. Below is an example from video step 1.6. Hans Christian Andersen - A writer for children or adults? 
While watching the video, you might think about the following questions:

- How does Hans Christian Andersen captivate his youngest listeners and readers?

- What does he mean when he gives this description of his work as a doublebottomed construction: "I seize on an idea for grown-ups and then tell the story to the little ones while always remembering that Father and Mother often listen, and you must also give them something for their minds."?

- What would be your immediate answer to these questions? Share your answers with other learners by posting them below.

Figure 9. Reflection questions from video step.

\section{Light facilitation}

On a course with thousands of participants, it is not possible to read through all posts, let alone give everyone feedback. Therefore, a light facilitation model was adopted in order to limit the workload for the participating educators:

\section{The light facilitation model consists of}

- a Welcome to week x e-mail, which is sent out every Monday during the 6 weeks the course is live. In this e-mail, the topics and activities of the week are presented and participants are encouraged to participate actively online.

- an End of week e-mail, which is sent out every Friday afternoon during the course. In this e-mail a short summary of participants' discussions is given - what points were made and conclusions arrived at? Often particularly interesting quotations from participants are included in these e-mails.

Figure 10. The two components of the light facilitation model.

The intention was that
"the community of participants [...] be the primary source of feedback for the majority of work contributed. This is in keeping with the participatory collaboration and commenting norms within social media."
(McAuley et al., 2010:11)

A student teacher was employed as course host to create these e-mails and monitor discussions on the FutureLearn platform.

\section{Methodology}

A mixed methods approach was employed in which both quantitative and qualitative data were collected. The methods were integrated at the design level (Frederiksen, 2013), i.e. the quantitative and qualitative data each played their own, separate role with regard to obtaining a more nuanced understanding of the key issues investigated: 
- How do you design for social learning and encourage a deep approach to learning?

- How do you support learning and learner interaction when a MOOC is live?

In the attempt to answer the first question, datasets from FutureLearn on learner engagement in both the first and the second run were obtained. Univariate analyses were performed to get an overview of the number of comments made by learners and to identify the step types that received the highest number of comments and thus were most effective in transforming learners into social learners. In addition, univariate analyses of the datasets were performed to discover types of learner engagement not captured in the number of comments. This was done to obtain a full overview of learner engagement and to gain insight into the frequency of the different types of learner engagement displayed.

Since the mere number of comments per step does not bear evidence of learning taking place, qualitative data have been included to study the social learners' experiences of the course. In the final week of the course, qualitative data were obtained from the participants in connection with step 6.11 which summarised the course and ended with this invitation:

\section{Take a moment to reflect on your participation in this course:}

- What have you learnt?

- What was your favourite part?

- What surprised you the most?

- What would you like to learn more about?

Post your response below, study and comment on the responses of fellow learners.

Figure 11. Course evaluation step.

518 participants left a comment on this step, contributing their answers to the questions posed. This is a response rate of $6.8 \%$ of people who started the course. Calculated on the basis of the number of social learners the response rate is $16.8 \%$. It is not possible to generalise on the background of the fairly low response rate, however, we can gain important information about the learning experience of social learners that can inform future course design. All comments posted on the step have been coded and grouped into themes.

In the final week of the second run of the course, qualitative data were obtained through a course step as described above. 169 participants left a comment on this step. These comments have been studied, coded and 
grouped into themes. Again the result can only be indicative due to the low response rate.

The observations and reflections of the educators and course host together with learner comments are also included as qualitative data that can help investigate and answer the second question posed: "How do you support learning and learner interaction when a MOOC is live?"

\section{Analysis and discussion}

\section{Evaluation of the first run}

MOOCs are very dynamic courses when it comes to enrolments and participation. People who are enrolled in a MOOC, but did not complete while the course was live, will still have access afterwards.

"That so many students are interacting with courses after they end is an unexpected way in which MOOCs differ from traditional classes."

(Anderson et al., 2014:4)

This means that completion rates will increase slightly from month to month as is illustrated in the two tables below:

\begin{tabular}{|l|r|r|r|}
\hline Participation figures from 29 November 2015 & & $\begin{array}{r}\text { FutureLearn } \\
\text { average \% }\end{array}$ \\
\hline Joiners (number of people enrolled in the course. Includes leavers) & 18,366 & & \\
\hline Leavers (number of people who have unenrolled) & 1,590 & 8.7 & 50 \\
\hline Learners (people who have viewed at least one step) & 7,613 & 41.5 & 81 \\
\hline Active Learners (completed at least one step) & 6,817 & 89.5 & 40 \\
\hline Returning Learners (completed steps in at least two weeks) & 3,387 & 44.5 & 38 \\
\hline Social Learners (have posted at least one comment) & 3,078 & 40.4 & 21 \\
\hline Fully Participating Learners (have completed at least 50\% of steps) & 1,336 & 17.5 & \\
\hline
\end{tabular}

Table 1. Participation figures from the first run, immediately after the course ended.

\begin{tabular}{|l|r|r|r|}
\hline Participation figures from 6 June 2016 & & $\begin{array}{r}\text { FutureLearn } \\
\text { average \% }\end{array}$ \\
\hline Joiners (number of people enrolled in the course. Includes leavers) & 18,369 & & \\
\hline Leavers (number of people who have unenrolled) & 2,783 & 15.2 & 50 \\
\hline Learners (people who have viewed at least one step) & 8,015 & 43.6 & 81 \\
\hline Active Learners (completed at least one step) & 7,152 & 89.2 & 40 \\
\hline Returning Learners (completed steps in at least two weeks) & 3,665 & 45.7 & 38 \\
\hline Social Learners (have posted at least one comment) & 3,159 & 39.4 & 21 \\
\hline Fully Participating Learners (have completed at least 50\% of steps) & 1,578 & 19.7 & \\
\hline
\end{tabular}

Table 2. Participation figures from the first run, 6 months after the course has ended.

Figures listed in tables 1 and 2 below the blue bar in the \% column are calculated on the basis of the number of learners. If the percentage of fully 
participating learners was calculated on the basis of the total number of joiners, the completion rate would be $7.3 \%$ immediately after the course but $8.6 \%$ half a year later. However, the completion rate would be $17.5 \%$ immediately after the course if calculated on the basis of the number of learners, i.e. those who actually started the course. The completion rate of $7.3 \%$ compares to the average completion rate reported for MOOCs. What is more interesting, however, is that more than 3,000 people around the world have engaged in analysis and discussion of Andersen and his works and around 1,500 people have completed the course. More than 8,000 people have browsed it.

Studying learner engagement in terms of comments posted can show to what degree the course design facilitated social learning.

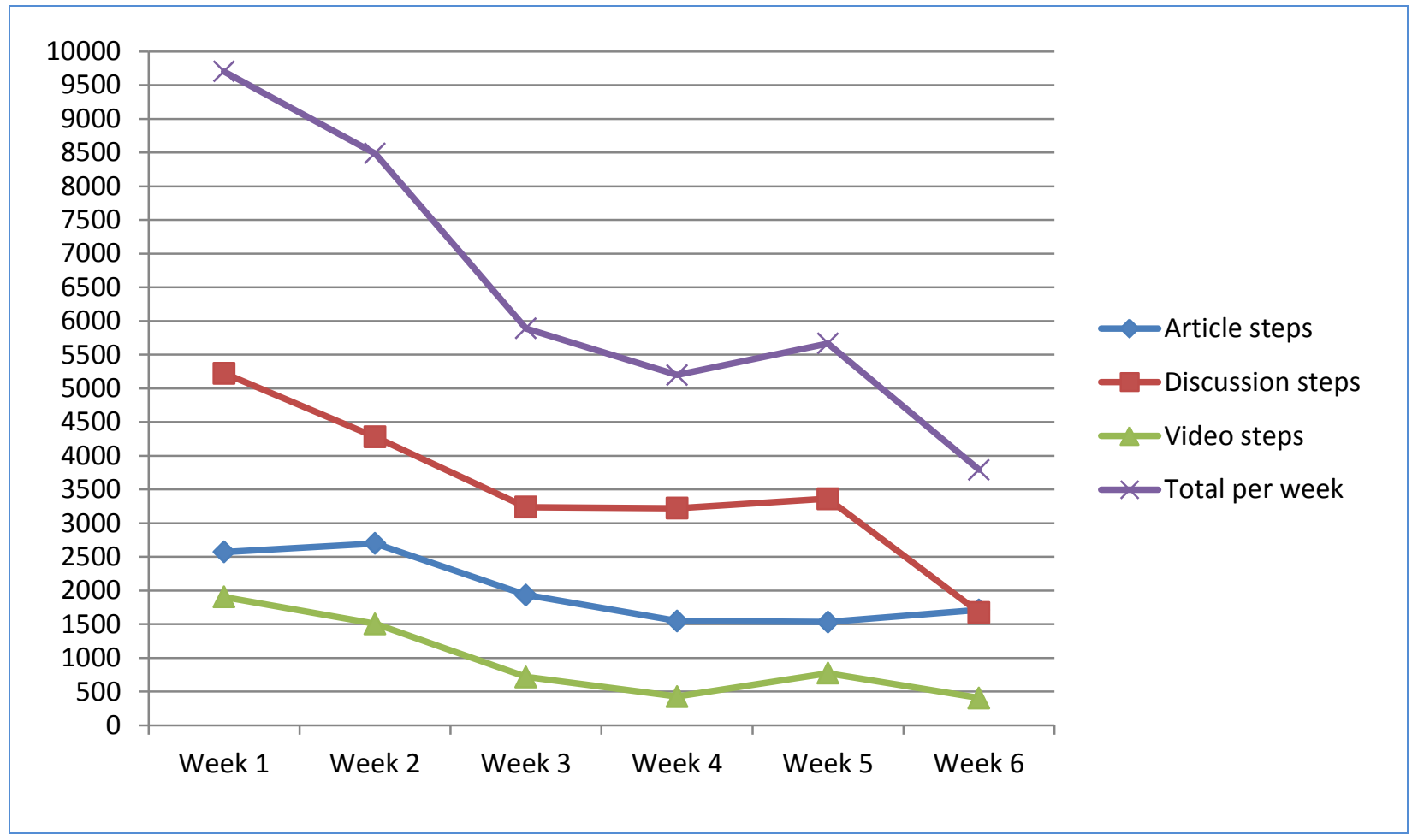

Figure 12. Number of comments made per step type per week and week totals.

The total number of comments was 38,736. The educators and the host made a total of 540 comments. This means that learners posted 38,196 comments which is an average of 4.8 posts per learner that started the course and an average of 12.1 per social learner, i.e. per learner that left comments on course steps. The figure above shows that discussion steps received the highest number of learner comments, then follow article steps, and video steps received the smallest number of comments. However, if we look at the average number of comments per step type taking into account the number of each step type, videos come in second and article steps are third. 


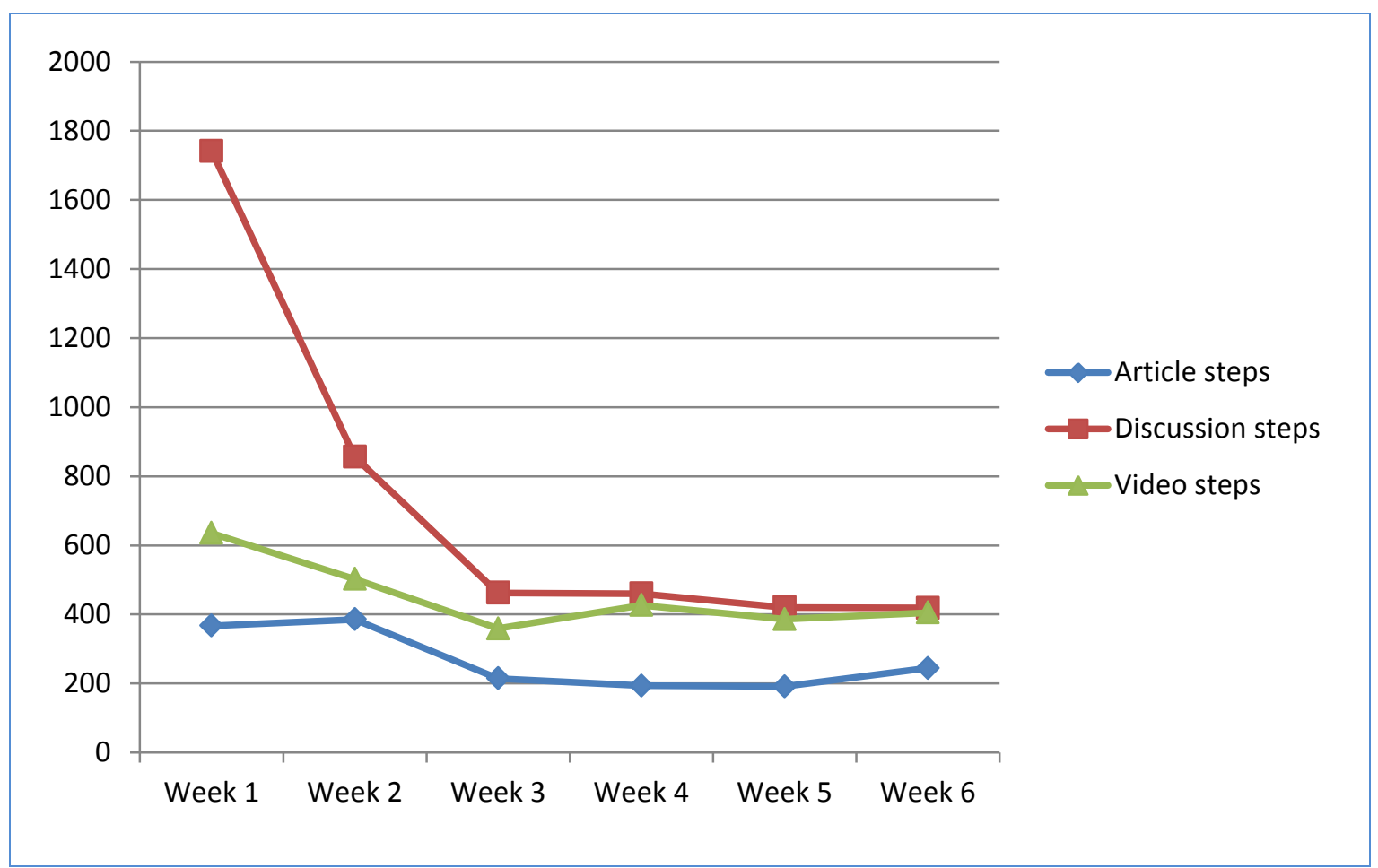

Figure 13. Average number of comments per step type per week.

The 10 steps that have received the highest number of comments are all discussion steps except for one, which is a video step marked green in the figure below. However, this video step contains questions for reflection which clearly have motivated learners to engage by posting comments, see p. 14. 


\section{Number of comments}

1.4 Your turn to introduce yourself 1.10 Visit HCA's world of images online

1.7 Who was HCA?

2.6 Read and discuss 'The Tinderbox' 1.6 HCA - A writer for children or adults?

2.4 Read and analyse 'The Blue Lihgt'

3.2 Read and discuss 'The Travelling Companion' and...

2.10Theme 2: HCA's special narrative style

2.12 Theme 3: A close look at the ending of 'The...

2.8 Theme 1: The folk tale inspiration in 'The.

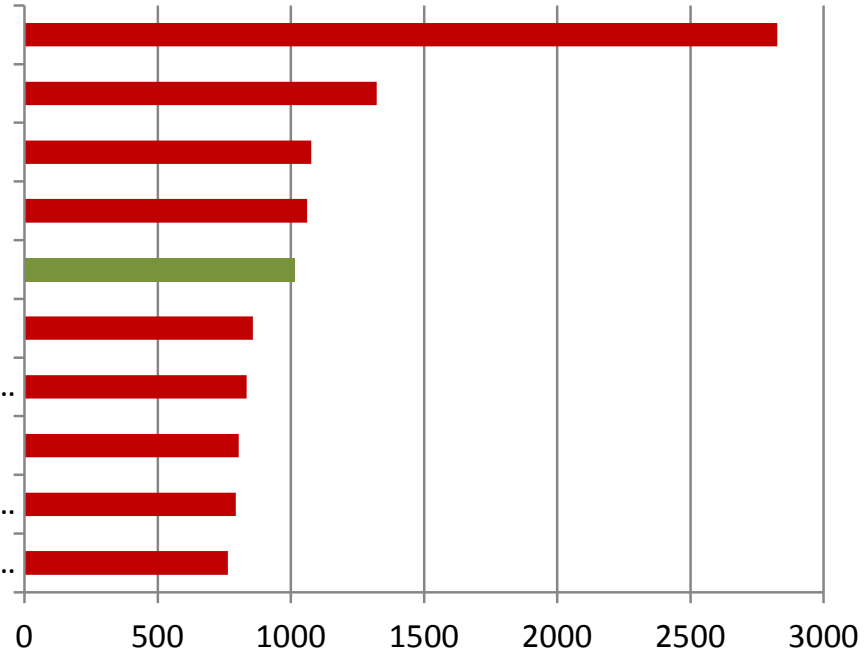

Figure 14. The 10 course steps that received the highest number of comments.

Step 1.4 that invited learners to engage and contribute to the course was a great success with a total of 2,826 contributions. In general, free discussion steps that called for learners' immediate thoughts and impressions were substantially more engaging than e.g. the educators' exemplary analyses as can be seen from the figure below that shows the average number of comments for the two step types per week. 


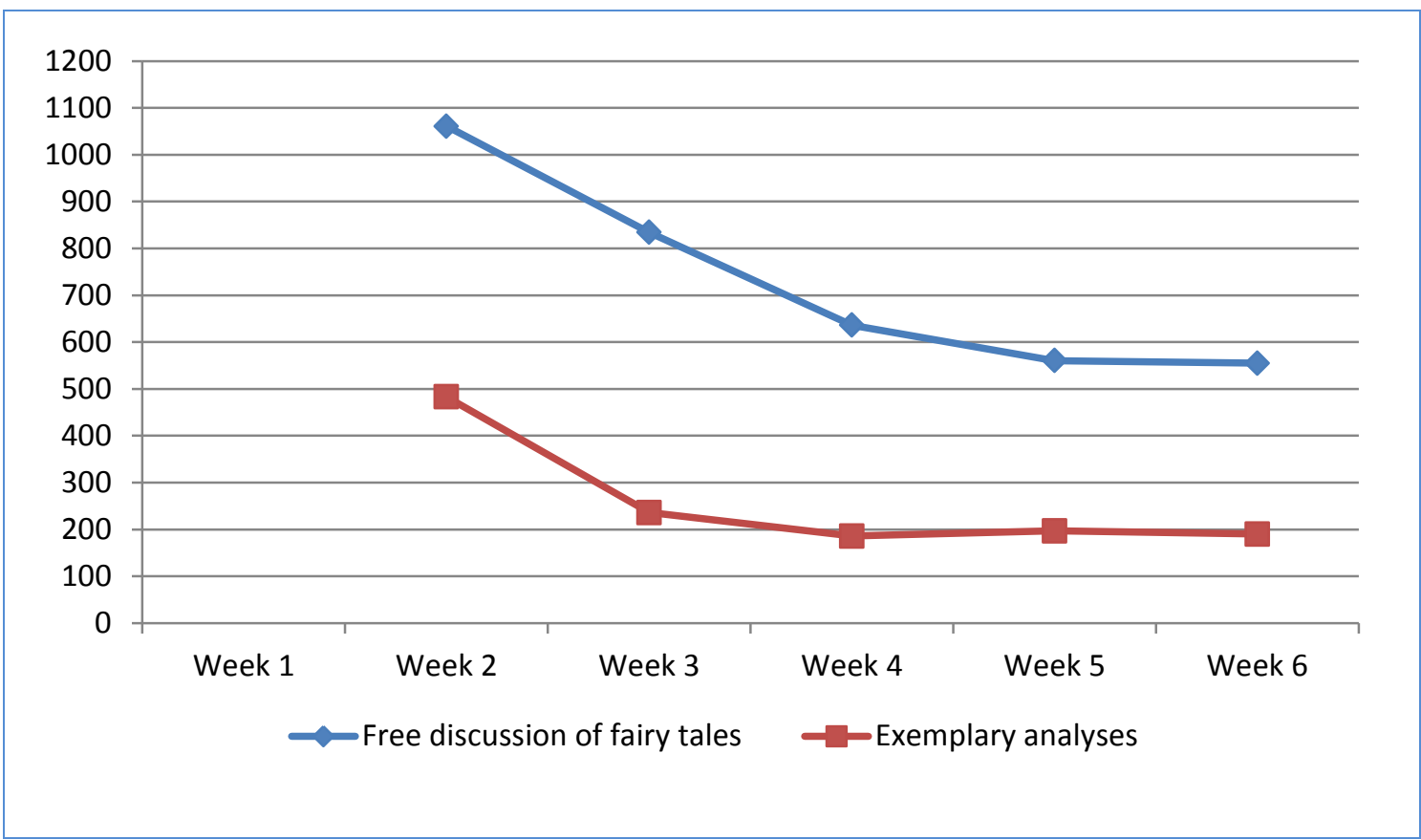

Figure 15. Average number of comments on free discussion steps compared to average number of comments on exemplary analyses steps.

The analysis of step types and number of comments above gives a clear picture of the type of step that is needed to motivate learner engagement and facilitate social learning. The most engaging step types are discussion steps and video steps. It should be noted that discussion steps in which learners can post immediate responses attract far the largest number of comments and thus facilitate social learning to the highest degree.

This article focuses on the engagement patterns of social learners, i.e. learners who post comments and engage in conversations with other learners. However, social learners made up $38 \%$ of learners, i.e. less than half of those who started the course. The most common type of engagement in the course was visiting and marking steps as completed as can be seen from the figure below. 


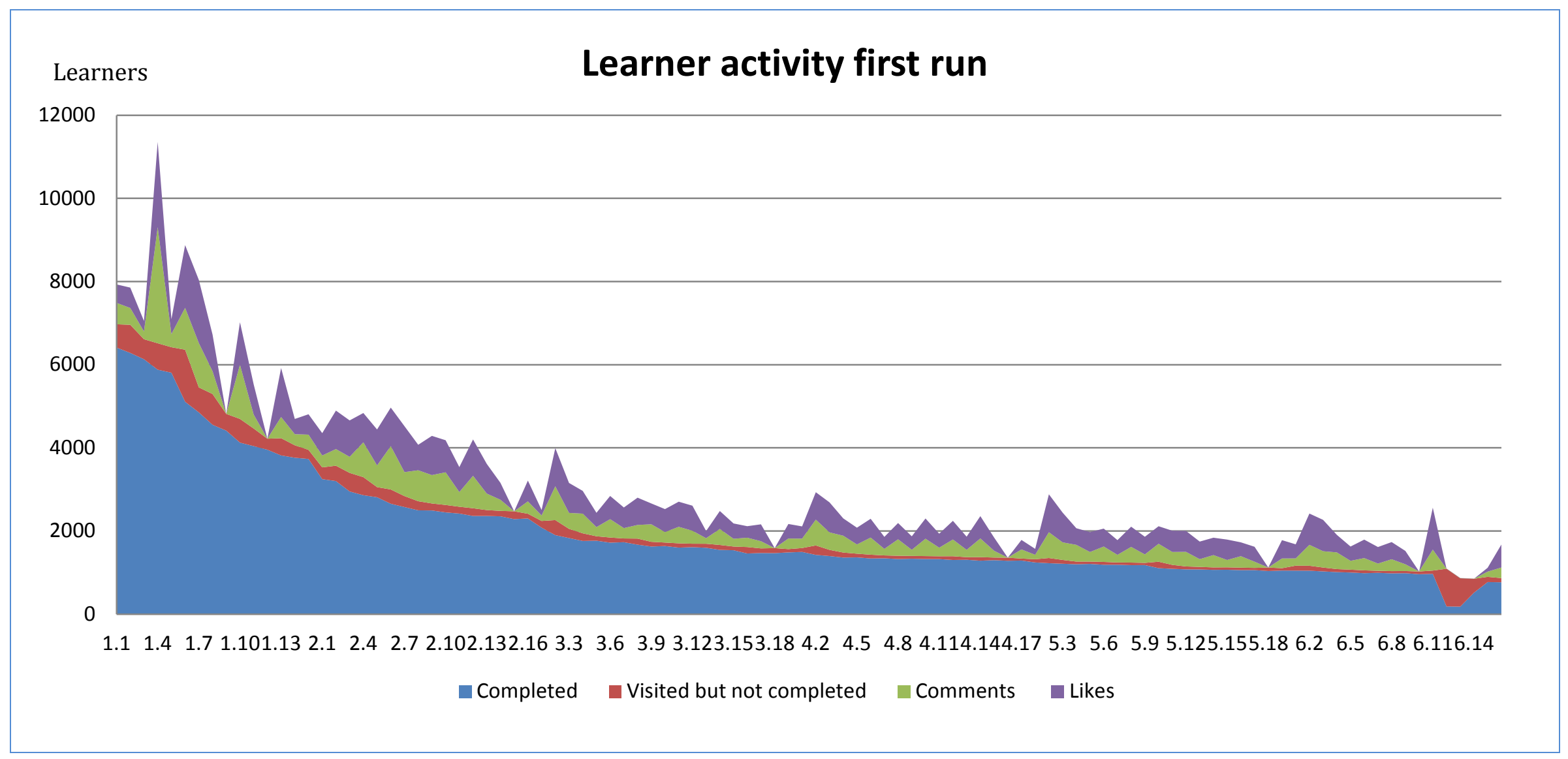

Figure 16. Learner activity per course step. Dataset from the FutureLearn platform. 
The figure above of learner engagement reveals peaks in activity at the start of each week of the course as identified by Ferguson et al. (2015) showing the importance of the welcome to week X e-mails sent out by the course host each Monday.

At the end of week 6 a large number of learners visit steps, but do not complete. These are the 3 steps connected to the peer-reviewed assignment. Only 186 learners submitted an assignment. Steps with no learner comments are the quizzes. The figure reveals that learners complete quizzes at the same rate as other step types. A steep decrease in learner engagement can be seen during the first two and a half weeks after which the level of engagement seems to stabilise. Placing a peer-reviewed assignment at the end of the course might influence the number of participants that complete week 6 . Alternatives should be considered. The peak just before the peer-reviewed assignment is the course evaluation step to which many learners responded. Quite interestingly, the figure reveals that the comments posted by learners are accompanied by a slightly larger number of likes. This is a social behaviour also worth studying in more detail.

Several questions arise when studying figure 16, the most pressing being how to transform those learners who simply mark steps as completed into social learners who post comments. It is also worth discussing whether it is desirable to transform learners into social learners. We have yet to discover what type of learning experience can be had from perusing course materials and the discussions of fellow learners. In addition, ways to retain learners after the second week should be investigated. FutureLearn has just launched a study group feature, the purpose of which is to enhance learner interaction and retention.

\section{Evaluation of the learning pathway and course plan provided}

Some participants found the persistent reliance on the analysis models throughout the course a bit tedious and repetitive. But the vast majority of social learners enjoyed working with the models and many of them stated that they had become better readers of fiction as a result.

The stories included in the course were arranged in the order listed on p. 9. This ensured that there would be a very clear progression throughout the course. The participants would first analyse the two folk tales and two of Andersen's fairy tales which borrow their story directly from folk tales. They would then progress to analyse stories of Andersen's own invention where his manipulations of the elements and structures of the folk tale are more radical and important to identify and discuss. In addition to this, there was a progression from tales without Christian or religious themes to tales containing such themes. As it was hoped, this very much fuelled the discussions of the degree of Andersen's contemporary relevance and 
universality. Many participants were surprised that such themes were part of Andersen's fairy tales and found it difficult to digest, but the majority found it interesting and eye-opening. Many valued the realization that literature has to be read with the historical and intellectual/philosophical context in mind.

Many participants also expressed their surprise that Andersen is such a rich and complex writer of stories and that, under the guise of writing tales for children, he could address issues and problems of his age which are still highly relevant today, which makes Andersen a modern kind of writer indeed.

\section{Evaluation of the use of light facilitation}

Facilitating the course was more challenging than first expected. The host read the comments posted and summed up the most significant discussions in the end of week e-mails, the purpose of which was to valorise and further stimulate social learning. Therefore, e-mails systematically quoted particularly original and inspiring comments from learners together with comments representing participants' reactions to course materials. However, light facilitation was insufficient. A relatively intense monitoring of the discussions was necessary to support participants. The composition of the course material raised a lot of questions. Many learners were surprised by the fact that the introductory materials not only included background information on Andersen and his contemporary society but also an article on biblical themes in the author's tales. Many readers were struggling to connect their preformed perception of the popular writer to the proposed material. Therefore, in the first run, a handful of participants were demanding feedback from the educators. The introduction of the analysis models also provoked a request for feedback as learners wished to be confirmed in their attempts to apply the models to the fairy tales. This request was meaningful with regard to learners adopting a deep approach to learning.

Engaging in discussions with a global audience was challenging and timeconsuming. The educators found themselves engaged in discussions of a very heterogeneous kind, operating at different levels of abstraction and adopting different discursive modes, which they would seldom experience in the conventional classroom. Interestingly, questions from the learners regarding literary analysis in general provoked the researchers to formulate - for the sake of the learners as well as themselves fundamental principles of the academic profession. Methodological approaches such as keeping the text open, inviting as many interpretations as possible, remaining sceptical towards biographical readings and explaining how seemingly anachronistic readings can be productive were regularly discussed. 
Learners' engagement and contributions in terms of pertinent links enriching the course material, the inventiveness of their analyses, and their interaction with fellow learners and educators contributed to making teaching in a MOOC a rewarding experience. This corresponds to the affective benefits of teaching in a MOOC identified by Ferguson \& Sharples (2014).

The outcome of the course

In the final week of the course, the participants provided us with qualitative data in step 6.11, which invited them to evaluate the course as outlined on p. 15. Table 6 shows the social learners' evaluation of their learning from the first run of the course:

1) What have you learnt?
$\begin{array}{llr} \\ \text { A. About HCA, his background and time } & 43 & (8.3 \%) \\ \text { B. Analysis models } & 98 & (19 \%) \\ \text { C. Discovering more layers in the text (symbols/allegories) } & 60 & (11.6 \%) \\ \text { D. About fairy tales and folktales } & 19 & (3.7 \%) \\ \text { E. Discovery/rediscovery of HCA's fairy tales } & 119 & (23 \%)\end{array}$

Table 3. Participants' evaluation of their learning.

The table above shows that the participants mainly learned how to use the analysis models just as they discovered or rediscovered Hans Christian Andersen's fairy tales. These points are connected: it is via the models that the participants discovered or rediscovered the fairy tales. The participants do not so much stress that they have learned about folk tales and fairy tales in general but they indicate that they have learned how Andersen specifically plays on and manipulates the basic structures of the folk tale. Thus, the course has achieved the main goal of instigating participants' discovery of the author's special modus operandi as a writer. However, many of the evaluations also state that being able to apply the analysis models is to be considered a transferable skill. The learners frequently specify that a supplementary outcome of the course is that they from now on tend to apply the models they have learned when viewing films or when reading other types of texts. Table 4 shows the participants' evaluation of their favourite part of the course. 


\section{2) What was your favourite part?}

$\begin{array}{lrr}\text { A. Specific fairy tales by HCA or simply reading HCA } & 39 & (7.5 \%) \\ \text { B. Learning about HCA, his background and contemporary society } & 12 & (2.3 \%) \\ \text { C. Analysis models } & 40 & (7.7 \%) \\ \text { D. Educators' exemplary analyses } & 169 & (32.6 \%) \\ \text { E. Passages from fairy tales read aloud in course videos } & 78 & (15 \%) \\ \text { F. Other learners' analysis and comments } & 86 & (16.6 \%) \\ \text { G. Analysing and interpreting the texts } & 47 & (9 \%) \\ \text { H. Rediscovering HCA (deeper/more complex readings) } & 48 & (9.3 \%) \\ \text { I. Response from teachers } & 41 & (7.9 \%)\end{array}$

Table 4. Participants' evaluation of their favourite part.

The table above shows that the participants who responded to the evaluation step to a great extent have acknowledged the educators' exemplary analyses. This contrasts with the fact that the free discussion steps are more popular in terms of activity in general than the educators' analyses (s. p. 18). This stresses that learner engagement cannot be measured solely by number of comments. Learners can engage with material alone and find the result satisfactory. Next to the educators' analyses, a favourite part of the course was the reading of other learners' analyses and comments. This point is significant in the sense that the course has proven to live up to the FutureLearn ideal of social learning, (see p. 4). It can be concluded that the course has been able to stimulate some participants to share and to co-construct learning by establishing creative and inclusive conversations.

Thirdly, a favourite part of the course was the reading aloud of Andersen's fairy tales. The learners frequently stated that these readings contributed to bringing the work of Andersen "alive" anew. This helped fulfil the main course goal of supporting participants' new readings of Hans Christian Andersen in a global context. Table 5 shows what participants found most surprising in the course.

\section{3) What surprised you the most?}

A. That HCA has written self-invented fairy tales

B. The difference between one's childhood memories of HCA's fairy tales as simple and the discovery of their many facets

C. The deviation of the fairy tales from genre expectations (no happy ending/cruelty etc.)

D. The religious meaning of the fairy tales

E. The complexity/modernity of the fairy tales

F. HCA as a visual artist

$27 \quad(5.2 \%)$

Table 5. What participants found most surprising. 
Clearly, participants were generally most surprised by the fact that Andersen's fairy tales convey religious meaning and by the complexity and modernity of the fairy tales. This point of the evaluation is very satisfactory since the goal defined by the educators was exactly to convey the facts that Andersen is a much more complex writer than his iconic status permits a world-wide audience to imagine. Table 6 shows what participants would like to learn more about.

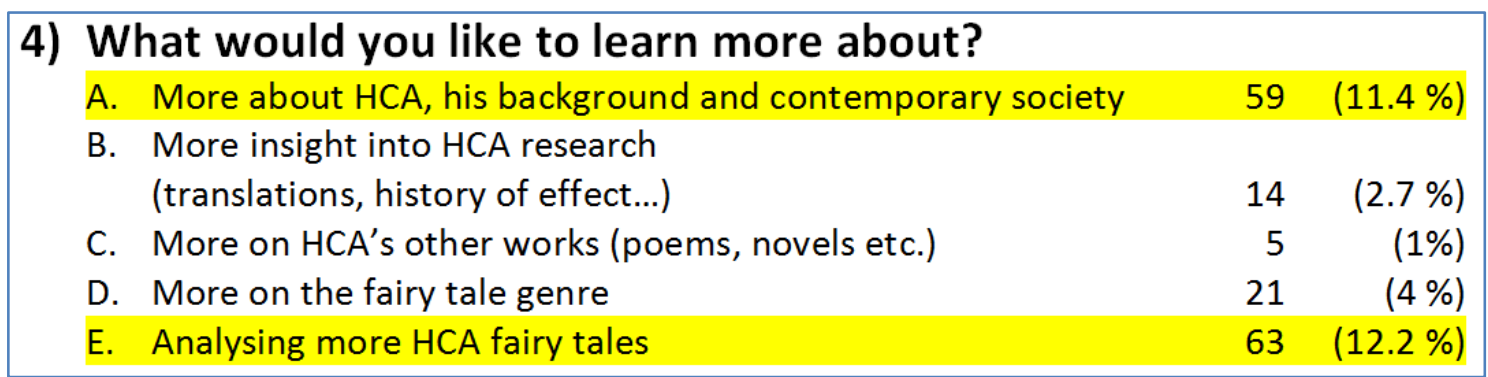

Table 6. What participants would like to learn more about.

Not surprisingly, the learners in particular would like to learn more about Andersen, his background and his time. The fact that the introductory material only partly focused on the author himself and the historical and social context of his works disappointed the learners. The evaluation also shows that the participants would like to analyse more of Hans Christian Andersen's fairy tales. In fact, the course has produced a demand for a HCA MOOC "part two". Table 7 shows the spontaneous evaluation of the outcome of the course.

\section{5) Learning outcome}
A. Want to read more of HCA's works
B. Want to visit Danmark/the HCA museum
C. Using knowledge and skills from the course professionally
D. Artistic inspiration

Table 7. Learners' spontaneous evaluation of the outcome of the course.

What is significant is that this evaluation was spontaneous and not an answer to a specific question. We can conclude that it is remarkable that so many social learners mention that the course has inspired them to engage in further readings of Hans Christian Andersen's works.

\section{Revised design for the rerun}

In the second run of the course, which took place in spring 2016, alterations were made to the course design in response to points of criticism from learners. The light facilitation model was used, but was supplemented with feedback to participants from the educators from the beginning of the course due to learners' demand for educator engagement in the first run. At the same time, an attempt was made to match 
expectations better by stating clearly, in the introductory material in week 1 , that first and foremost, the course builds on interaction between participants and to a lesser extent on direct feedback from the educator team.

In order to give participants access to the educator team and minimise the workload, two live, online Q \& A sessions were included in the course design of the rerun. In these sessions, the researchers would answer questions posted by participants on the FutureLearn platform. Additional material on Hans Christian Andersen's background and life was also added since learners had requested more in-depth information on this in the first run.

\section{Evaluation of the rerun of the course}

The table below shows the participation figures for the rerun of the course.

\begin{tabular}{|l|r|r|r|}
\hline Participation figures from 6 June 2016 & & $\begin{array}{r}\text { FutureLearn } \\
\text { average }\end{array}$ \\
\hline Joiners (number of people enrolled in the course. Includes leavers) & 7,887 & & \\
\hline Leavers (number of people who have unenrolled) & 798 & 10.1 & \\
\hline Learners (people who have viewed at least one step) & 3,605 & 45.7 & 50 \\
\hline Active Learners (completed at least one step) & 3,100 & 86.0 & 81 \\
\hline Returning Learners (completed steps in at least two weeks) & 1,428 & 39.6 & 40 \\
\hline Social Learners (have posted at least one comment) & 1,280 & 35.5 & 38 \\
\hline Fully Participating Learners (have completed at least 50\% of steps) & 554 & 15.4 & 21 \\
\hline
\end{tabular}

Table 8. Participation figures from the second run of the course.

The table above shows that $15.4 \%$ of learners completed the course. If the figure is calculated on the background of the number of people enrolled (joiners), the completion rate is $7 \%$. However, more than 3,000 people have viewed course material and may have browsed comments. 1,280 people have engaged in analysis and discussions and more than 500 have completed the course. The table below illustrates learner engagement in terms of comments made per step type per week and course total: 


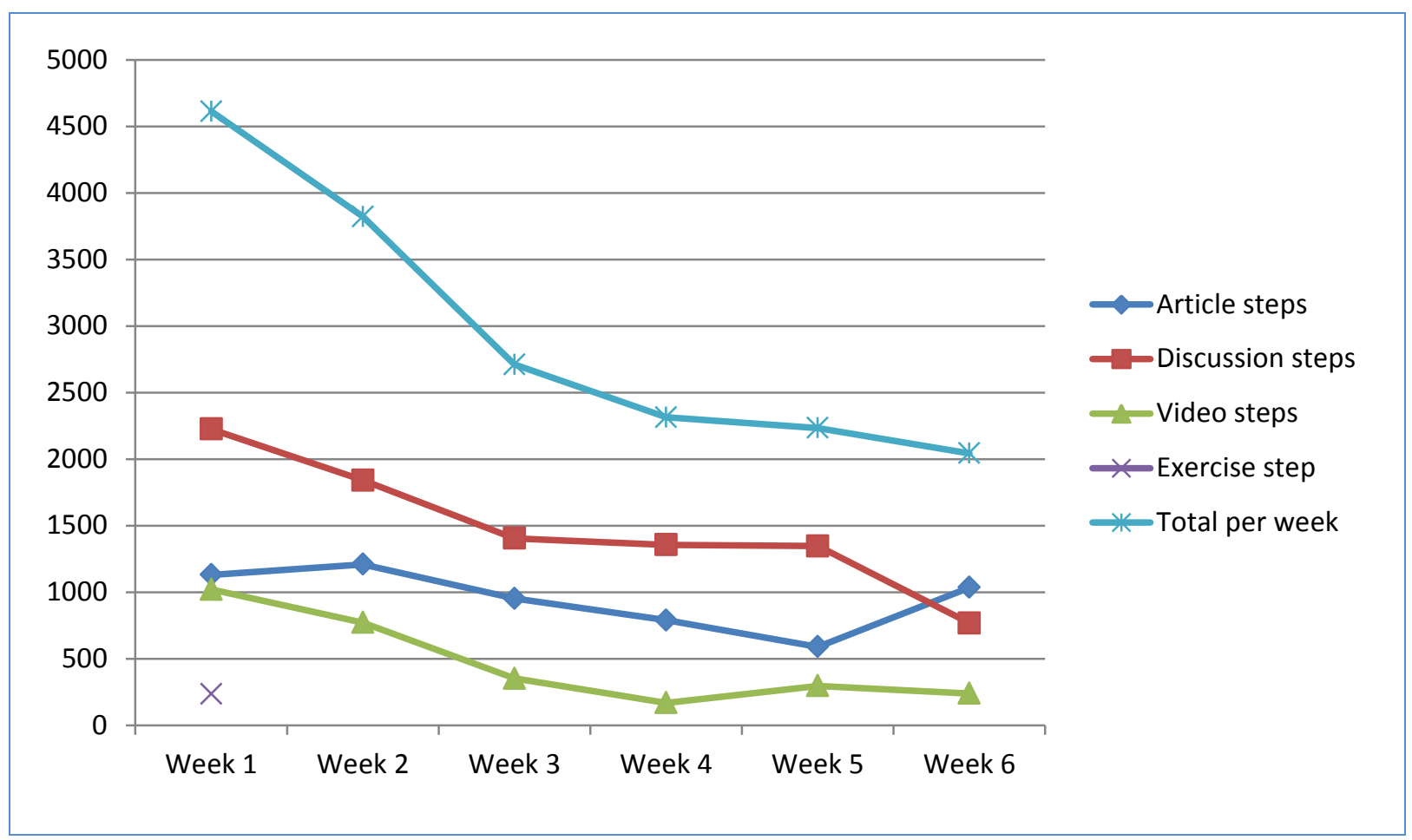

Figure 17. Number of comments made per step type per week and week totals, second run.

There was a total of 17,734 comments on the course. The educator and the host made a total of 463 comments. This means that learners posted 17,271 comments which is an average of 13.5 posts per social learner. A slight increase compared to the first run. As in the first run, discussion steps received the highest number of learner comments, then follow article steps and video steps. However, if we look at the average number of posts per step type, video steps come in second and receive more comments than the article steps. Comments on video steps even surpass comments on discussion steps in week 6 . 


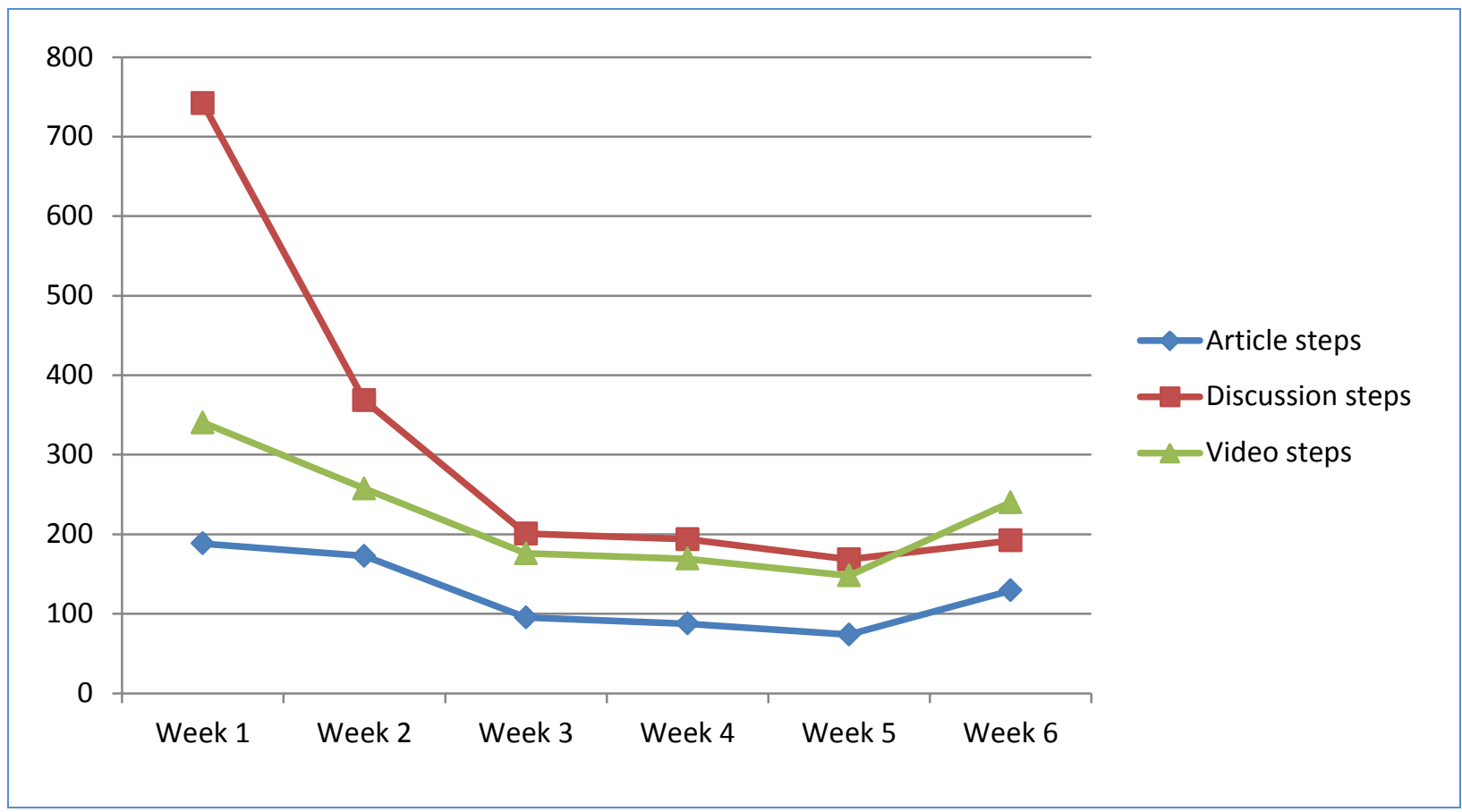

Figure 18. Average number of comments per step type per week.

The 10 steps that have received the highest number of comments are all discussion steps except for two. One video (marked in green below) and one article (marked in blue below) step have also made it to the list.

\section{Number of comments}

1.4 Your turn to introduce yourself

1.6 HCA - A writer for children or adults?

1.8 The story of HCA told by himself, new step

1.11 Visit HCA's world of images online

2.6 Read and discuss 'The Tinderbox'

2.4 Read and analyse 'The Blue Light'

2.12 Theme 3: A close look at the ending of 'The...

2.10 Theme 2: HCA's special narrative style 6.12 Summary of the course 3.3 Read and discuss "The Travelling Companion'...

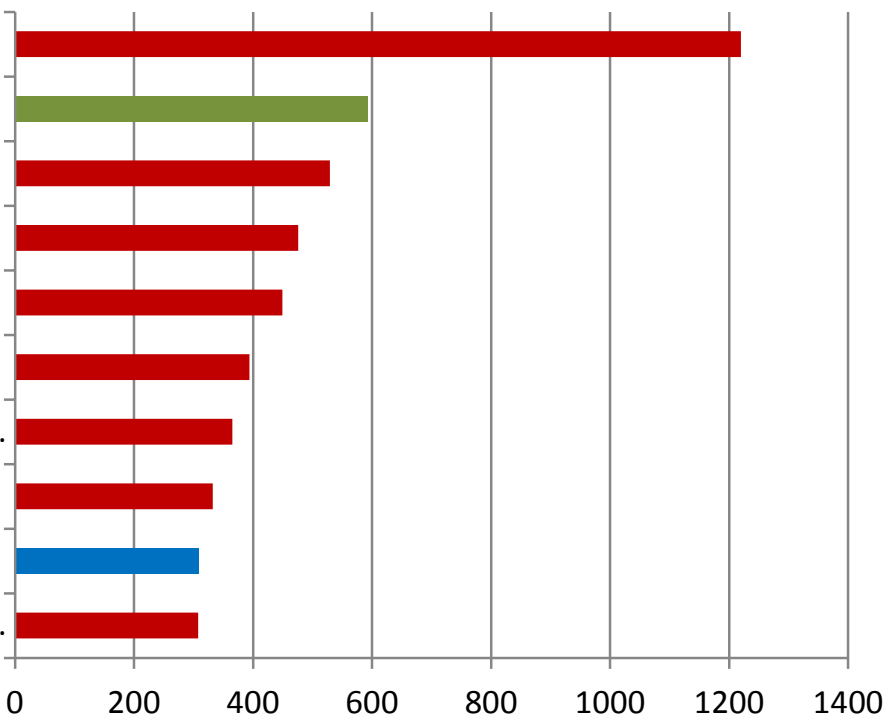

Figure 19. The 10 course steps that received the highest number of comments. 
As in the first run, step 1.4 that invited learners to engage and contribute their own story of how they first met HCA was the highest scoring step in terms of learner posts. The table below shows that free discussion steps are more popular than the educators' analyses in terms of number of comments made. Not to the same degree, however, as in the first run.

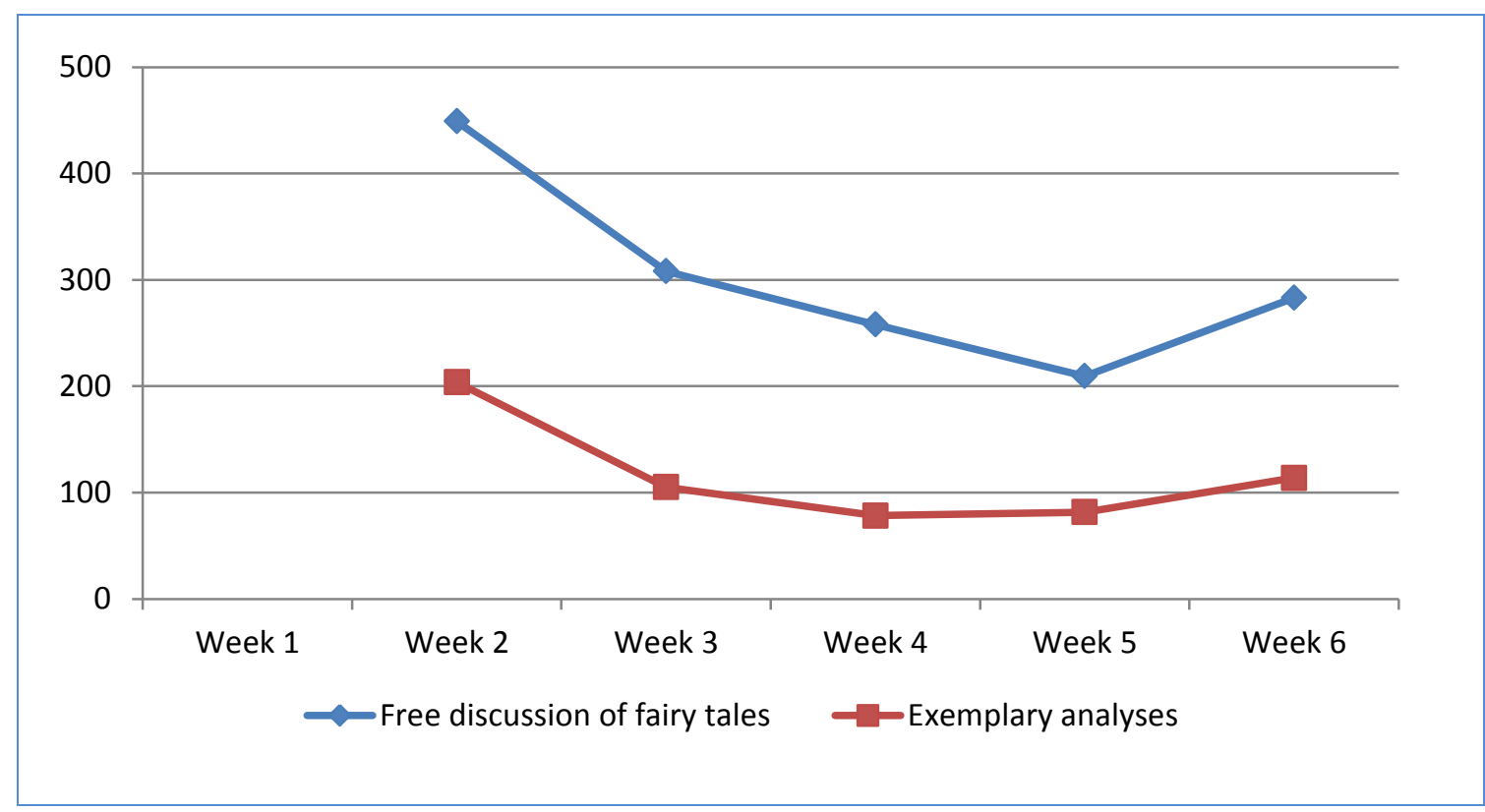

Figure 20. Free discussion steps compared to educator's analysis steps.

The analysis of step types and number of comments in the rerun supports the results from the first run and clearly indicates what types of steps motivate learners to engage in social learning, namely discussion and video steps. 


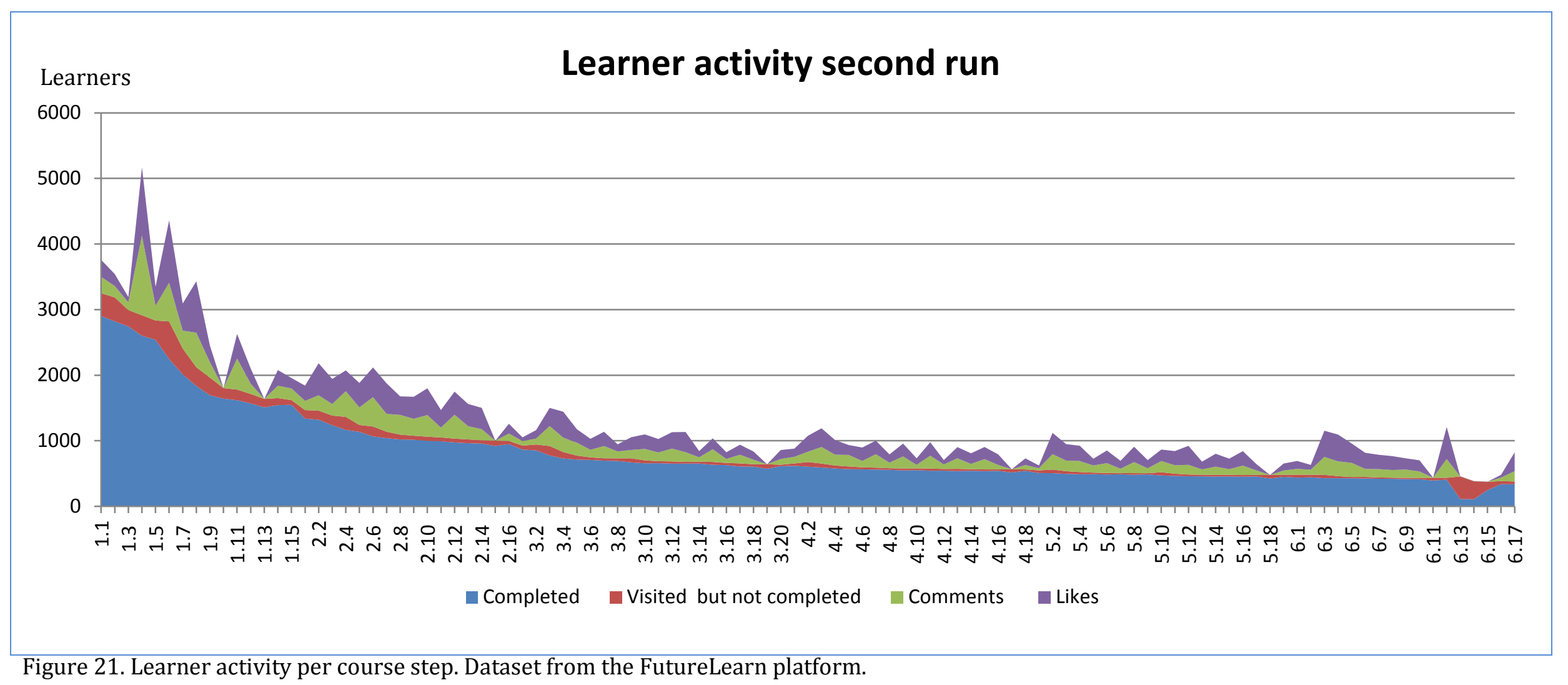


The figure depicting learner engagement (figure 21 above) in the rerun also reveals peaks in activity at the start of each week of the course confirming the importance of the welcome to week X e-mails. Likewise, in the rerun, a steep decrease in learner engagement can be seen during the first two and a half weeks after which the level of engagement seems to stabilise. Only 112 learners submitted the peer-reviewed assignment mirroring the results from the first run. As in the first run, the comments posted by learners are accompanied by a slightly larger number of likes.

The analysis of learner engagement in the second run thus stresses the necessity of finding ways to retain learners after the second week. How can MOOC designs be optimised for learner interaction and retention? As mentioned FutureLearn has launched a study group feature in an effort to enhance interaction and retention. When looking at the HCA MOOC design it is worth noting that after the first two weeks, the MOOC repeats the same pattern or learning pathway, cf. figure 6 above, albeit with new fairy tales and new analysis tasks. Some learners have indicated that they see this as monotonous, and it may be the reason why some learners do not complete the course. It would be interesting to design new and different learning pathways for weeks 3-6 of the MOOC and study the effect on retention.

\section{Course evaluation}

Just as was the case in the first run of the course, the participants were invited to evaluate the course in the final week of the rerun (in step 6.12). The questions posed were identical to the first run and to enable comparison participant responses were coded using the themes from the first run. Table 9 shows the participants' evaluation of what they have learned from the course.

\section{1) What have you learnt?}

$\begin{array}{llr}\text { A. About HCA, his background and time } & 25 & (14.8 \%) \\ \text { B. Analysis models } & 30 & (17.6 \%) \\ \text { C. Discovering more layers in the text } & 16 & (9.5 \%) \\ \text { D. About fairy tales and folktales } & 19 & (11.2 \%) \\ \text { E. Discovery/rediscovery of HCA's fairy tales } & 27 & (16.0 \%)\end{array}$

Table 9. What have you learnt?

The main difference is that an increasing number of learners $114.8 \%$ versus $8.3 \%$ ) mention that they have learned about Andersen, his background and his time. This is satisfactory and is most likely the result of the material added to the course. However, the learners have first of all learned to use the analysis models. Perhaps more surprisingly, fewer learners than in the first run mention that they have discovered or rediscovered Andersen's fairy tales (16.0\% versus $23 \%)$. In the rerun they mention that they have learned about fairy tales and folktales in general (11.2\% against $3.7 \%$ ). This indicates that they have paid more attention to 
the theoretical aspect of discovering the fairy tales in the rerun. Table 10 shows the participants' evaluation of their favourite part of the course.

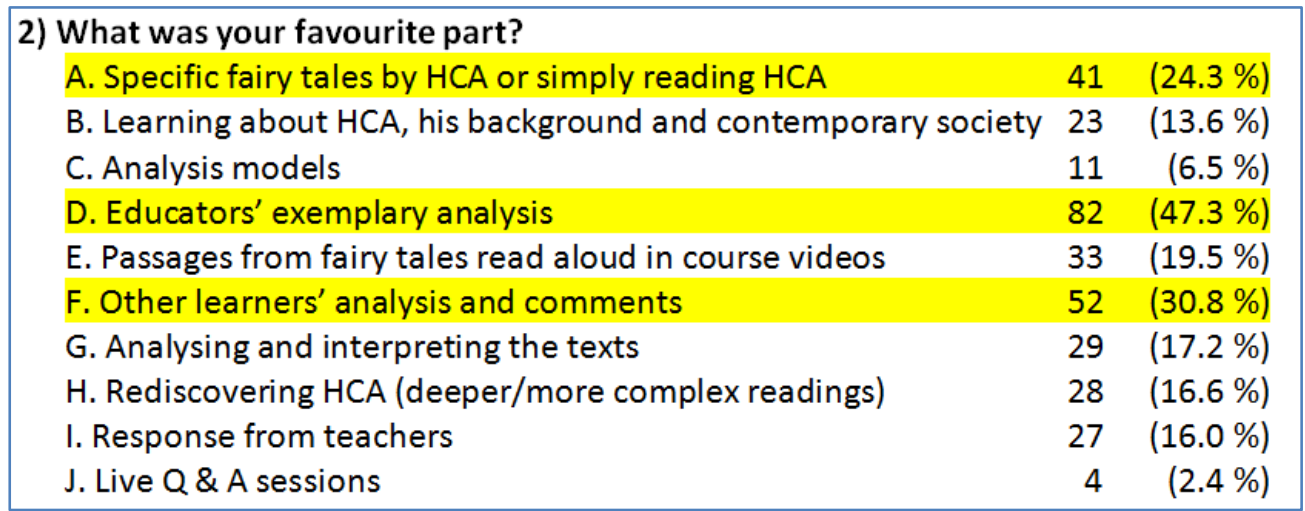

Table 10. Learners' favourite part of the course.

Generally, the comparison of the two evaluations shows that the rerun with additional course material, an increased amount of feedback and live Q \& A sessions has increased the social learners' appreciation in all the pertinent criteria. The rerun, thanks to the additional material, has generated more satisfaction concerning information on Andersen's life, background and time (13.6 \% versus $2.3 \%)$.

But most noticeable, in the rerun the mere reading of Andersen's fairy tales became a favourite part (24.3\% versus $7.5 \%$ ). Relatedly, the educators' analyses of the fairy tales were absolutely the preferred part of the course ( $47.3 \%$ versus $32.6 \%$ ). This can be explained by the increased feedback on participants' questions regarding the educators' analyses, which were not modified in the rerun. The read aloud passages from the fairy tales were even more appreciated in the rerun than in the first run $(19.5 \%$ versus 15 $\%)$, participants indicate that these passages create interest and pleasure.

In the rerun, almost twice as many learners appreciated other learners' analyses and comments (30.8\% versus $16.6 \%$ ). This is a significant improvement that supports participants' social learning and a deep approach to learning. We believe that this is another outcome of the increased feedback provided by the educators. The educators focused very much on valorising the learners' creative analyses and this fact most probably helped the learners to stimulate each other and to appreciate the possibility of producing various readings of the fairy tales. The evaluation also shows an important increase in satisfaction concerning the learners' experiences analysing and interpreting the texts ( $17.2 \%$ versus $9 \%)$. This means that the course has achieved the goal of making learning a social and participatory activity. Table 11 shows what the participants would like to learn more about. 


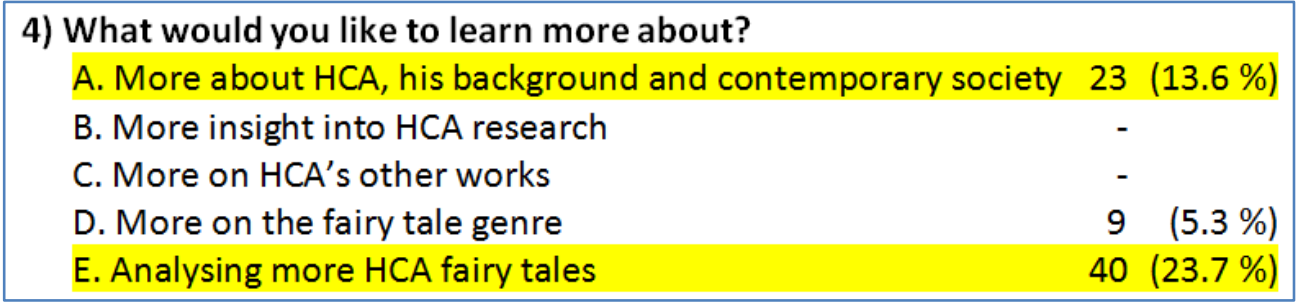

Table 11. What would you like to learn more about?

Even though the rerun of the course included additional material on Hans Christian Andersen's life, background and time, it is significant that the learners would like even more information on the subject (13.6\% versus $11.3 \%$ ). Even more important, though, is the fact that the improved course has succeeded in increasing the demand of a "part two" of the course (23.7 $\%$ in the second run versus $12.2 \%$ in the first run). The more we offer to the learners about the subject, the more they wish to explore it.

Evaluation of the use of new translations and live $Q \& A$ sessions The new translations were noticed and the quality praised by several participants. It resulted in interesting debates about translation in general. This was particularly noticeable during the two live sessions where learners were invited to send questions to the researchers, who would then answer them in a live panel debate. The questions focused among other things on the difficulty of translating Andersen into foreign languages and the historical mistranslations and misunderstandings that exist. Generally, the questions veered away from the course's core content and addressed biographical factors, technical and methodological issues, research traditions and literary analysis in general.

\section{Conclusion}

The HCA MOOC on the FutureLearn platform has made it possible for learners around the world to connect with Hans Christian Andersen experts from Odense, Denmark. The purpose of this article was to examine whether such a MOOC is simply one-way communication, i.e. dissemination to the masses or whether MOOCs can be designed for social learning and facilitate a deep approach to learning. It can be concluded that a learning design based on social constructivist learning and utilising tools that support learners' interaction with course materials, other learners, the course host as well as the educators has the potential to support learners' social learning and encourage a deep approach to learning. Inline conversation, activity feeds and follow functions make it easy for learners to contribute and engage in conversation and thus encourage and facilitate social learning.

Two aspects of the learning design in particular encouraged a deep approach to learning: the carefully designed learning pathway and the 
planned progression from week to week. The composition of steps engaged learners in the analysis of fairy tales before reading the educator's sample analysis. This structure was enriched by an on-going conversation between learners in which they discussed each other's analyses and possible interpretations. The simple analysis models provided participants with useful tools that ensured focused and relevant analyses.

Learner engagement in the form of learners posting comments was seen as a success criterion cf. the social constructivist learning design. The conclusion is that learner engagement can be triggered through discussion steps and by including questions for reflection in article and video steps. The majority of the steps in the HCA MOOC are article steps; however, social learners engage with discussion and video steps to a higher degree. Therefore further development of the HCA MOOC should involve identification of article steps that can be transformed into video steps. An interesting experiment would be to transform some of the educators' analyses steps into videos to examine whether more user engagement and activity can be generated around these components.

The analysis of learner engagement reveals that the most common learner behaviour is to mark steps as completed. Can more learners be transformed into social learners, and is this the ultimate goal? Research into the learning experience achieved by browsing course materials and discussions are needed to gain knowledge on how best to facilitate quality learning in MOOCs. In addition, many learners disengage during the first 2 and a half weeks of the course and the question is how MOOC design can be optimised to retain these learners. Could the solution be to provide new and different learning pathways after the initial two weeks to reengage learners instead of repeating the same pattern as in the HCA MOOC?

The educators' active support of the learners remains a crucial source of encouragement and stimulation. The comparison between the first and the second run of the course proves that light facilitation is insufficient to facilitate a deep approach to learning and to support social learning. It is necessary in particular to offer a minimum of feedback on learners' attempts to analyse texts. The more the educators recognize, discuss and validate the participants' own readings of the fairy tales, the more the participants invest themselves and, crucially, the more prepared they are to learn from one another.

\section{References}

Anderson, A.; Huttenlocher, D.; Kleinberg, J. \& Leskovec, J. (2014). Engaging with Massive Online Courses. Presented at the International World Wide Web Conference, April 7-11, Seoul, Korea. Retrieved on 2/6 2016 from http://cs.stanford.edu/people/ashton/pubs/mooc-engagementwww2014.pdf 
Christensen, O. (2016). MOOSL - Democratizing Education with Social Learning MOOCs. IN: Ubachs, G. and Konings, L. (Eds.) (2016).

Conference Proceedings. The Online, Open and Flexible Higher Education Conference. 2016. EADTU. Pp. 632-642.

Czerniewicz, L.; Deacon, A.; Small, J. \& Walji, S. (2014). Developing world MOOCs: A curriculum view of the MOOC landscape. IN: Special Issue on MOOCs. Journal of Global Literacies, Technologies and Emerging Pedagogies, Volume 2, Issue 3, July 2014, pp. 122-139.

Daniel, J. (2012). Making Sense of MOOCs: Musings in a Maze of Myth, Paradox and Possibility. IN: Journal of Interactive Media in Education. Retrieved on 31/3 2013 from http://jime.open.ac.uk/articles/10.5334/2012-18/.

Eisenberg, M. \& Fischer, G. (2014) "MO0Cs: A Perspective from the Learning Sciences" in J. L. Polman et al. (Eds.), Learning and Becoming in Practice: 11th International Conference of the Learning Sciences (ICLS) 2014, Boulder, pp. 190-197. Retrieved on 2/6 2016 from http://13d.cs.colorado.edu/ gerhard/papers/2014/ICLS-MOOCS.pdf.

Ferguson, R. \& Sharples, M. (2014). Innovative Pedagogy at Massive Scale. IN Rensing et al. (Eds.) (2014). Open Learning and Teaching in Educational Communities. 9th European conference on Technology Enhanced Learning, EC-TEL 2014. Proceedings. Springer, pp. 98-111.

Ferguson, R., \& Clow, D. (2015). Examining engagement: analysing learner subpopulations in massive open online courses (MOOCs) (pp. 51-58). ACM Press.

Ferguson, R., Clow, D., Beale, R., Cooper, A. J., Morris, N., Bayne, S., \& Woodgate, A. (2015). Moving Through MOOCS: Pedagogy, Learning Design and Patterns of Engagement. In G. Conole, T. Klobučar, C. Rensing, J. Konert, \& É. Lavoué (Eds.), Design for Teaching and Learning in a Networked World (Vol. 9307, pp. 70-84). Cham: Springer International Publishing.

Fischer, G. (2015): “Massively Open Online Courses (MOOCs) as Components of Rich Landscapes of Learning", Proceedings of Academia Europaea \& The Wenner-Gren Foundations Conference: "Emerging Models of Learning and Teaching in Higher Education: From Books to MOOCs?", Stockholm, May 2015 (in print). Retrieved on 11 July 2016 from: http://13d.cs.colorado.edu/ gerhard/papers/2015/TAcademiaEuropea-M00C.pdf

Frederiksen, M. (2013). Integration I 'mixed methods' forskning: Metode eller design. IN Metode \& Forskningsdesign. Nr. 1, 2013, p. 17-40. 
FutureLearn (undated). About section on www.futurelearn.com. Retrieved on 15/8 2016 from https://www.futurelearn.com/about.

Haggard, S. (2016). The Maturing of the MOOC: Literature Review of Massive Open Online Courses and Other Forms of Online and Distance Learning (2016). BIS Research Paper Number 130. Department for Business Innovation and Skills, UK. Retrieved on 2/6 2016 from: https://www.gov.uk/government/uploads/system/uploads/attachmen t data/file/240193/13-1173-maturing-of-the-mooc.pdf

Hébert, L. (2006), « The Actantial Model », in Louis Hébert (dir.), Signo [online], Rimouski (Quebec), http://www.signosemio.com/greimas/actantial-model.asp.

Heilesen, S. (2014). Når talen er om MOOC - Nedslag i diskussionen af en ny teknologi. LUG-Projektet, delprojekt A 2014. DUN-konferencen, 5. Maj, 2014.

Jih, H. J. (1996). The impact of learners' pathways on learning performance in multimedia Computer Aided Learning. Journal of Network and Computer Applications. 19 (4), pp. 367-380.

Kop, R. (2011). The Challenges to Connectivist Learning on Open Online Networks: Learning Experiences during a Massive Open Online Course. In. International Review of Research in Open and Distance Learning. Vol. 12.3. March 2011, pp. 19-38.

Laurillard, D. (2012). Teaching as a Design Science - Building Pedagogical Patterns for Learning and Technology. New York: Routledge.

Marton F. \& Säljö R. (1976). On qualitative differences in learning. I Outcome and Process. British Journal of Educational Psychology. Volume 46, Issue 1, February 1976, pp. 4-11.

McAuley, A.; Stewart, B.; Siemens, G. \& Cormier, D. (2010). The MOOC model for digital practice. Massive Open Online Courses. Digital ways of knowing and learning. Retrieved on 10/4 2013 from: http://elearnspace.org/Articles/MOOC Final.pdf

Pappano, L. (2012). The Year of the MOOC. New York Times. Novemeber 2, 2012. Retrieved on 15/8 2016 from http://www.nytimes.com/2012/11/04/education/edlife/massiveopen-online-courses-are-multiplying-at-a-rapidpace. $h$ tml?pagewanted $=$ all \& $\mathrm{r}=0$.

Propp, V. (1928). Exerpts from Morphology of the Folk Tale. Translation 1968. The American Folklore Society and Indiana University. Available at: http://homes.di.unimi.it/ alberti/Mm10/doc/propp.pdf 
Rai, L. \& Chunrao, D. (2016). Influencing Factors of Success and Failure in MOOC and General Anaysis of Learner Behavior. In: International Journal of Information and Education Technology, Vol. 6, No. 4, April 2016.

Raposo-Rivas, M., Martínez-Figueira, E., \& Sarmiento-Campos, J.-A. (2015). A Study on the Pedagogical Components of Massive Online Courses. Comunicar, 22(44), 27-35.

Sharples, M., Adams, A., Ferguson, R. Gaved, M., McAndrew, P., Rientes, B., Weller, M. \& Whitelock, D. (2014). Innvoating Pedagogy 2014. Open University Innovation Report 3. Milton Keynes: The Open University.

University of Edinburgh (2013). MOOCs @ Edinburgh 2013 - Report \#1.

Walton, M. (2014). Social learning. Blog post from the FutureLearn Partners forum. 18 December 2014.

Yuan, L. \& Powell, S. (2013). MOOCs and Open Education: Implications for Higher Education. A white paper. Jisc Cetis. Retrieved on 9/5 2013 from http://publications.cetis.org.uk/2013/667.

Yousef, A. M. F., Chatti, M. A., Schroeder, U., Wosnitza, M. \& Jakobs, H. (2014). IN: Zvacek, S et al. (Eds.) (2014). Proceedings of the $6^{\text {th }}$ International Conference on Computer Supported Education. Barcelona, pp. 9-20. 